\title{
1 Digital Twins for Bioprocess Control Strategy 2 Development and Realisation
}

\section{Christian Appl, André Moser, Frank Baganz, Volker C. Hass}

4 Abstract: New innovative Digital Twins can represent complex bioprocesses, including the

5 biological, physico-chemical, and chemical reaction kinetics, as well as the mechanical and physical characteristics of the reactors and the involved peripherals. Digital Twins are an ideal tool for the rapid and cost-effective development, realisation and optimisation of control and automation strategies. They may be utilised for the development and implementation of conventional controllers (e.g. temperature, dissolved oxygen...), as well as for advanced control strategies (e.g. control of substrate or metabolite concentrations, multivariable controls), and the development of complete bioprocess control. This chapter describes the requirements Digital Twins must fulfil to be used for bioprocess control strategy development, and implementation and gives an overview of research projects where Digital Twins or "earlystage" Digital Twins were used in this context. Furthermore, applications of Digital Twins for the academic education of future control and bioprocess engineers as well as for the training of future bioreactor operators will be described. Finally, a case study is presented, in which an "early-stage" Digital Twin was applied for the development of control strategies of the fedbatch cultivation of Saccharomyces cerevisiae.

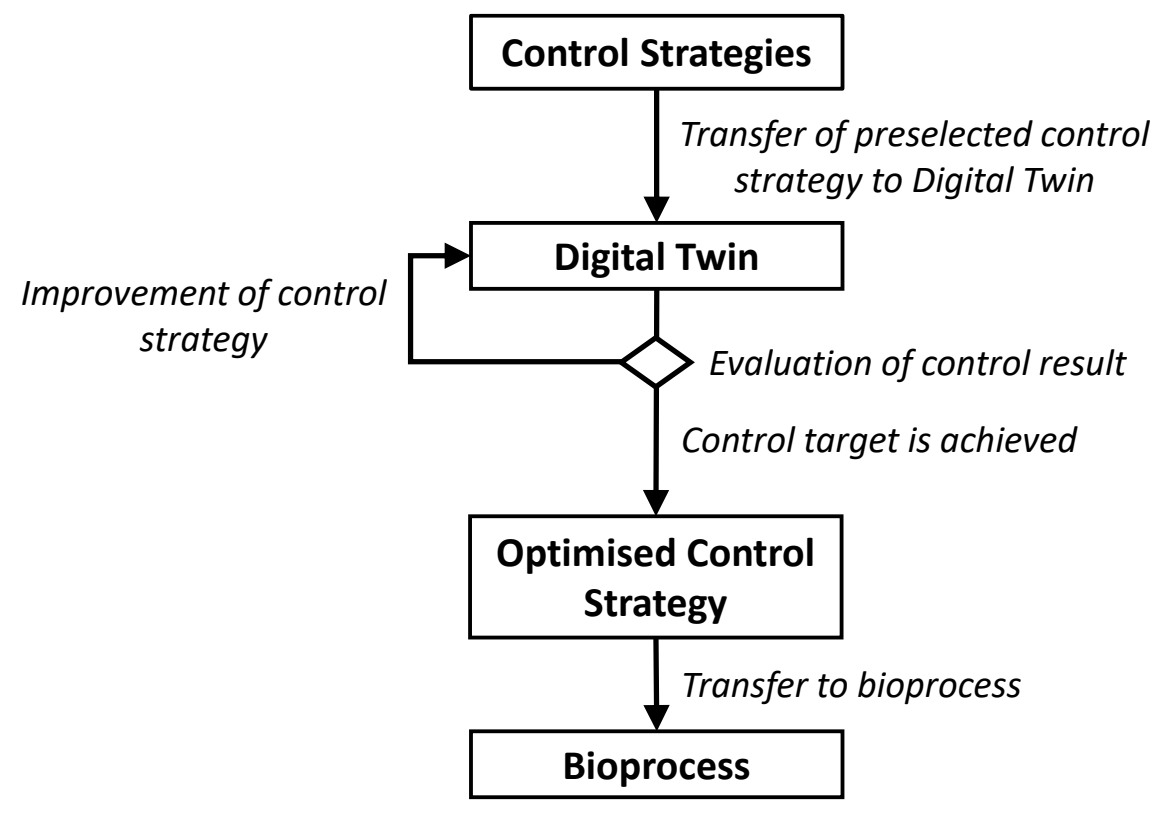


Keywords: Digital Twin, Bioprocess, Control strategy development, Operator training simulator (OTS)

\section{Contents}

1 Introduction

2 Advanced bioprocess control development, realisation and optimisation using Digital Twins.

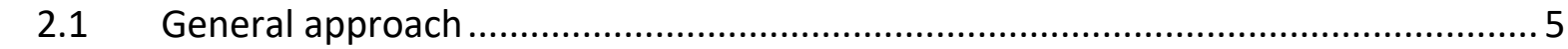

2.2 Design of Digital Twins as control strategy development tools ............................. 6

2.2.1 Software tools for the design of Digital Twins .............................................. 7

2.3 Control strategies for bioprocesses ............................................................ 9

2.3.1 Advanced and model-based control strategies

2.3.2 Open-loop-feedback-optimal (OLFO) control strategy

2.4 Digital Twin based development, realisation and optimisation of control strategies for bioprocesses

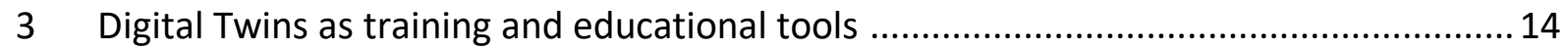

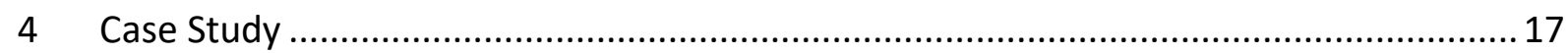

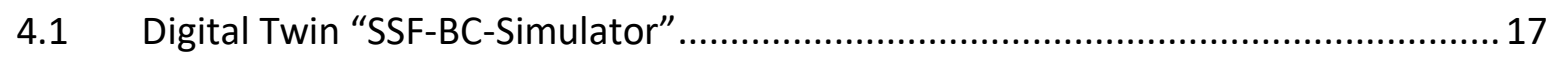

4.1.1 Parametrisation of the Digital Twin "SSF-BC-Simulator" ................................. 18

4.1.2 Digital Twin "SSF-BC-Simulator" for the development of control strategies....... 21 4.2 Digital Twin based development of control strategies for the cultivation of $S$. cerevisiae

4.2.2 Development of respiratory quotient (RQ) feedback control for the cultivation of S. cerevisiae . 
516 References.

52

\section{Nomenclature and Abbreviations}

$\begin{array}{ll}A M B C & \text { Advanced and model-based control } \\ C H O & \text { Chinese hamster ovary (mammalian cell) } \\ D C U & \text { Digital control unit } \\ D L L & \text { Dynamic link library } \\ D O & \text { Dissolved oxygen } \\ \text { DoE } & \text { Design of experiment } \\ \text { EtOH } & \text { Ethanol } \\ \text { GUI } & \text { Graphical user Interface } \\ \text { MPC } & \text { Model-predictive control } \\ \text { NMPC } & \text { Nonlinear model predictive control } \\ \text { OLFO } & \text { Open-loop-feedback-optimal strategy } \\ \text { OTS } & \text { Operator training simulator } \\ P & \text { Product (Ethanol) } \\ P & \text { Proportional (P-controller) } \\ P C S & \text { Process control system } \\ P I & \text { Proportional integral (PI-controller) } \\ P I D & \text { Proportional integral derivate (PID-controller) } \\ P \& I D & \text { Piping and instrumentation diagram } \\ R Q & \text { Respiratory quotient } \\ S & \text { Substrate (Glucose) } \\ S S F-B C & \text { Simultaneous saccharification, fermentation, and biocatalysis } \\ S T R & \text { Stirred tank reactor } \\ X & \text { Dry biomass density (S. cerevisiae) } \\ & \end{array}$




\section{Introduction}

The development of control strategies for bioprocesses poses huge challenges for process engineers. The need for new tools that can help with this task, therefore, is enormous. Optimisation of controllers during production runs is usually exceedingly difficult or even impossible. Thus, bioprocess operation must be interrupted for control optimisation. Interruptions of a production run, as well as inadequate control, can lead to immense financial losses, which must be avoided. A promising approach to this issue is the application of Digital Twins. The development or optimisation of control strategies may be performed using this tool, thus leading to a shortened start-up time for the newly developed or optimised bioprocess control scheme.

In the early 2000s, the Digital Twin concept was first applied in mechanical engineering [1-3]. Digital Twins are often seen as virtual representations of physical systems and can map the entire life cycle of the physical system [2]. Various authors already published definitions of the term Digital Twin [1-5]. This chapter as well as [Chapter: Moser, Brüning, Hass "Mechanistic Mathematical Models as a Basis of Digital Twins for process optimization"], which is also in this book series are mainly based on the definition given by El Saddik [3]:

"Digital twins are (...) digital replications of living as well as non-living entities that enable data to be seamlessly transmitted between the physical and virtual worlds."

For further explanations refer to [Chapter: Moser, Brüning, Hass "Mechanistic Mathematical Models as a Basis of Digital Twins for process optimization"], which is also in this book series.

This chapter covers Digital Twins for the development, optimisation and realisation or implementation of bioprocess control strategies on a real process that correspond to the Digital Twin definition given by El Saddik [3], as well as operator training simulators (OTSs), which are considered by the authors to be "early-stage" Digital Twins. Although OTSs are mainly used for training purposes, they also offer enormous potential for bioprocess development, similarly to Digital Twins. OTSs are usually adapted to the real process during development or when there are significant changes in the real process.

In the last section of this chapter, a case study is presented where an "early-stage" Digital Twin was used to develop process control strategies for the fed-batch cultivation of Saccharomyces cerevisiae (S. cerevisiae) in a stirred tank reactor (STR). 


\section{Advanced bioprocess control development, realisation and optimisation} using Digital Twins

Initial approaches for the application of Digital Twins as a tool for control strategy development have been successfully established in the chemical industry [4-7]. Due to the recognised potential, the application of Digital Twins as a tool for the development of control strategies is also gaining increasing interest for bioprocesses.

Within this chapter, the suitability of Digital Twins for the development, optimisation and realisation of bioprocess control strategies will be highlighted. First, the general approach when using Digital Twins for the development of control strategies is outlined. Subsequently, the requirements that Digital Twins must fulfil to be used as a tool for the development of control strategies and which challenges control engineering must overcome in the case of bioprocess control is described. Finally, in the presented case study, application examples for the utilisation of Digital Twins for bioprocess control strategy development are described.

\subsection{General approach}

In the author's opinion, the quality of Digital Twins is of utmost importance for the development of control and automation strategies [8]. The basis of applicable Digital Twins is a dynamic mathematical model, which can map the biological, chemical and physical phenomena of the real process in detail [9]. This dynamic mathematical process model should be coupled to a graphical user interface (GUI) [9]. Users can monitor and make changes to the virtual process using graphical icons in the GUI. From the author's point of view, it is advantageous, if the structure of the GUI corresponds to the process control system (PCS) on the physical counterpart. The Digital Twin GUI is a functional image, derived from the P\&ID (piping and instrumentation diagram) flow chart of the real bioprocess and thus, also serves as a realistic replica of important parts of the control and automation model. A realistic GUI of a Digital Twin can, therefore, be used to check the usability (including typical operating errors), as well as the control and automation of the real bioprocess. The model of a Digital Twin is parameterised based on real process data to represent the behaviour of the physical process [10]. Another possibility to keep Digital Twin and the real process as identical as possible is an online and at-line data connection between the "twins". This enables the adaption of the Digital Twin using online and at-line data, which is particularly useful if the real process frequently changes its characteristics. 
115 During process development or optimisation, Digital Twins can be used for the following applications:

117

(1) Determination of suitable controller types

(2) Improvement of controller performance

(3) Improvement of the overall process performance through appropriate process control strategies

If, for example, suitable controllers (e.g. for temperature, dissolved oxygen or product concentration) should be designed, the controller type can be selected based on simulations with the Digital Twin. An early step in controller selection should be the definition of appropriate control targets [8]. When controlling the temperature of a bioreactor, such control targets are e.g. a short rise time, a high control accuracy (especially important for temperature-sensitive organisms, particularly mammalian cells ) or a low overshoot. For example, the conventional proportional integral derivative (PID) control can be compared to a more complex nonlinear model predictive control (NMPC) by applying them to a Digital Twin. If both control strategies yield equally good control results, PID control would be preferred, because it is cheaper and easier to handle.

Once a control strategy has been able to control the virtual process satisfactorily, the results are transferred to the real process. The transfer of the developed control strategy from the Digital Twin to the real process may be further simplified if the Digital Twin and the real process are linked to the identical PCS [8].

To illustrate the general approach of process control design utilising a Digital Twin, the case study in section 4 presents the selection and optimisation of suitable control strategies for the cultivation of S. cerevisiae.

\subsection{Design of Digital Twins as control strategy development tools}

To utilise a Digital Twin for the development of both conventional (e.g. single loop PID control) and advanced control (e.g. multivariable controllers, model predictive control), it must fulfil specific requirements that have to be considered during the design process of the Digital Twin. According to Hass [11], desirable characteristics of a functionally useful Digital Twin include realistic simulation of the biological, physical and chemical processes, accurate representation of automation and control actions and a GUI with a similar 'look and feel' to that of the real 
145

146

147

148

149

150

151

152

153

154

155

156

157

158

159

160

161

162

163

164

165

166

167

168

169

170

171

172

173

174

175

plant [11]. Mathematical models used in Digital Twin development are classified broadly as mechanistic, non-mechanistic or hybrid models $[9,10,12]$. In this context, a model refers to a mathematical representation of certain aspects of a real-world object or phenomenon. Nonmechanistic models use sets of experimental data to represent observed phenomena by fitting parameters based on the available datasets. Mechanistic models seek to represent experimental observations based on the underlying biological, chemical, and physical mechanisms occurring in the system. Mechanistic models offer excellent predictive capabilities beyond the original experimental conditions used for model development. By contrast, non-mechanistic models only offer very restricted predictive capabilities [2, 9-12]. Mathematical modelling for a Digital Twin involves several key steps. The first step is a definition of the process using appropriate diagrams and charts. A process flow diagram and a piping and instrumentation diagram (P\&ID) are excellent starting points for system definition $[10,13,14]$. Ideally, verbal process description and expected modelling targets including levels of model accuracy are specified at this stage. Following system definition, appropriate mathematical models that sufficiently describe the physical, biological, and chemical processes in the system are formulated based on literature research $[9,14]$. To structure the process model, it has been suggested to divide the model into smaller sub-models. One approach is the shell model introduced by Blesgen et al. $[15,16]$ and extended by Hass et al. [17]. In this case, the overall mathematical model of the Digital Twin is divided into a biological sub-model, physico-chemical sub-model, a reactor sub-model, a plant and peripheral submodel as well as a control and automation sub-model (see also [Chapter: Moser, Brüning, Hass "Mechanistic Mathematical Models as a Basis of Digital Twins for process optimization"], which is also in this book series). Depending on the requirements of the Digital Twin, the shell model can be extended or reduced in complexity.

\subsubsection{Software tools for the design of Digital Twins}

Further steps in Digital Twin development include model implementation using suitable tools, model parameterisation and finally model validation using experimental data. Several modelling tools for the development of Digital Twins are readily available and easy to use, but they do not provide the flexibility and adaptability needed to model all aspects of bioprocesses, as they were originally designed for modelling of chemical processes. With the increasing focus on bioprocess development, significant effort has been invested in the 
176 development of model libraries for bioprocess unit operations in recent years. Software 177 systems for parameter estimation and computation of algebraic and differential equations 178 provide a user-friendly and adaptable environment for model development and 179 implementation of Digital Twins [9-11].

180 For the design of Digital Twins or "early-stage" Digital Twins, that can be used for the 181 development, optimisation and realisation of control strategies, there are already a variety of 182 software packages available. Table 1 lists a selection of vendors and associated software 183 products and summarises the most important features of the respective software packages.

184 Most of the Digital Twin development tools listed are designed for the chemical industry (e.g. 185 UniSim Competency Suite [18] or IndissPlus [19]), but some are also suitable for the 186 development of bioprocess Digital Twins (e.g. WinErs/C-eStIM [20, 21], PerceptiveAPC [22] or 187 TMODS [23]).

188 Table 1 Digital Twin development tools for the process industry (adapted from [10])

\begin{tabular}{|c|c|c|}
\hline Vendor & Software package & Key features (according to the vendors) \\
\hline Aspen Technology & $\begin{array}{l}\text { Aspen OTS Framework } \\
{[24]}\end{array}$ & $\begin{array}{l}\text { Data communication links handle the exchange of data } \\
\text { and commands. } \\
\text { User interfaces support different views of the } \\
\text { application for operators, engineers, and training } \\
\text { instructors. }\end{array}$ \\
\hline $\begin{array}{l}\text { DuPont Industrial } \\
\text { Biosciences }\end{array}$ & TMODS [23] & $\begin{array}{l}\text { Fully customised to match plant configuration, } \\
\text { conditions, compositions, control schemes, safety } \\
\text { interlocks and GUls. }\end{array}$ \\
\hline Honeywell & $\begin{array}{l}\text { UniSim Competency } \\
\text { Suite [18] }\end{array}$ & $\begin{array}{l}\text { Customisable framework for a structured operator } \\
\text { competency management system. } \\
\text { Interactive, navigable, panoramic 2D field operator } \\
\text { training environment based on high-resolution } \\
\text { photographs of the facility. }\end{array}$ \\
\hline $\begin{array}{l}\text { Ingenieurbüro Dr.- } \\
\text { Ing. Schoop GmbH }\end{array}$ & WinErs/C-eStIM $[20,21]$ & $\begin{array}{l}\text { Modular process automation system. } \\
\text { Provides a flexible, process control and simulation } \\
\text { system suitable for industrial, didactical and research } \\
\text { applications. } \\
\text { Complete process monitoring and operation via a user- } \\
\text { editable GUI. } \\
\text { Simple graphical editing of controls and simulations via } \\
\text { block structures, logic plans and GRAFCET with no prior } \\
\text { programming knowledge required. }\end{array}$ \\
\hline $\begin{array}{l}\text { Wood Group (John } \\
\text { Wood Group) }\end{array}$ & ProDyn [25] & $\begin{array}{l}\text { Offers off-the-shelf and customer-specific solutions. } \\
\text { Operator training and learning systems, abnormal } \\
\text { situation management, and process troubleshooting. } \\
\text { Can be used to develop and test plant procedures. }\end{array}$ \\
\hline
\end{tabular}




\begin{tabular}{|c|c|c|}
\hline NovaTech & $\begin{array}{l}\text { NovaTech Ethanol } \\
\text { Training Simulator, D/3 } \\
\text { DCS [26] }\end{array}$ & $\begin{array}{l}\text { Allows breweries, biofuels facilities, and other process } \\
\text { plants to develop real-to-life plant simulations. } \\
\text { Training on complex process control techniques and } \\
\text { correcting behavioural patterns. } \\
\text { Trend visualisation, process analytics and control loop } \\
\text { performance monitoring and optimisation. }\end{array}$ \\
\hline Outotec & HSC Sim [27] & $\begin{array}{l}\text { Various simulation and modelling applications based on } \\
\text { independent chemical reactions and process units. } \\
\text { Graphical flowsheet and spreadsheet type process unit } \\
\text { models. }\end{array}$ \\
\hline $\begin{array}{l}\text { Perceptive } \\
\text { Engineering }\end{array}$ & PerceptiveAPC [22] & $\begin{array}{l}\text { Tools for monitoring, analysis or predictive control, in a } \\
\text { logical, intuitive interface, for both batch and } \\
\text { continuous processes. } \\
\text { Training module and easy-to-use templates to tune and } \\
\text { validate the right controller (also model-predictive } \\
\text { control (MPC)) for the process. }\end{array}$ \\
\hline Protomation BV & Protomation OTS [28] & $\begin{array}{l}\text { A real-time dynamic model that covers the complete } \\
\text { operating window. } \\
\text { Allows accurate simulation and training in the entire } \\
\text { operating range of the plant (from start-up conditions } \\
\text { up to normal operation and upset conditions). }\end{array}$ \\
\hline CORYS & IndissPlus [19] & $\begin{array}{l}\text { Models based on first principles of chemical engineering } \\
\text { with rigorous thermodynamics calculation and physical } \\
\text { component properties database. } \\
\text { Can accurately represent plant start-up and shutdown, } \\
\text { in addition to a variety of design and abnormal } \\
\text { operating conditions. }\end{array}$ \\
\hline Siemens & SIMIT OTS [29] & $\begin{array}{l}\text { Based on the dynamic modelling of the plant. } \\
\text { Flexible modelling is possible, the process can be } \\
\text { emulated as a whole or in parts. }\end{array}$ \\
\hline SimGenics & SimuPACT [30] & $\begin{array}{l}\text { The integrated software platform enables engineers to } \\
\text { develop high fidelity, full-scope power and process plant } \\
\text { simulators. } \\
\text { Intuitive GUI which allows engineering analysis and } \\
\text { operator training on the same simulation platform. }\end{array}$ \\
\hline Yokogawa & Yokogawa OTS [31] & $\begin{array}{l}\text { OTS constantly synchronises with the plant control } \\
\text { system. } \\
\text { Able to predict plant internal states and plant responses, } \\
\text { contributing to optimised plant operations. }\end{array}$ \\
\hline
\end{tabular}

\subsection{Control strategies for bioprocesses}

190 The multi-phase system in a bioprocess sets highest demands on measurement and control 191 technology [32-34]. To maintain optimal conditions for the entire process, the composition of 192 the liquid phase (e.g. medium), the suspended gas phase (e.g. oxygen, carbon dioxide) and the 193 dispersed solid phase (e.g. cells, cell assemblies, enzymes) must be monitored continuously 194 [32]. Furthermore, complex dynamics showing a wide range of time constants make it difficult to control the process without sufficient process knowledge [32]. For example, the induction 
196

197

198

199

200

201

202

203

204

205

206

207

208

209

210

211

212

213

214

215

216

217

218

219

of a gene through a temperature shift or the addition of a chemical inducer affects the process several minutes after the expression of the desired protein because the formation of a metabolically active protein will cause a time delay. This kind of knowledge must be available and utilised for successful bioprocess control based on detailed process analytics [32-35].

The choice of control strategies mainly depends on the selected bioprocess and the available reactor type [33, 34]. In general, controllers are divided according to continuous (e.g. PID control, soft sensor control) and discontinuous behaviour (e.g. model predictive control (MPC) or nonlinear model predictive control (NMPC)) [34]. Controllers with continuous behaviour calculate and transmit continuous control signals based on the current process characteristics [34]. Among the best-known continuous controllers are the "conventional" controllers like two-point-, three-point-, proportional- (P-), proportional-integral- (PI-) or PID-controllers. Controllers with discontinuous behaviour only calculate control signals or profiles at specific process points [34].

As an example, conventional control strategies such as PI or PID control are generally used to control temperature [34]. In many cases, the control system should be able to maintain the desired setpoint, due to the rather weak influence of disturbances. More complex processes, such as the enzymatic hydrolysis of lignocellulosic biomass, can be significantly improved by using advanced temperature control. In this process, endoglucanase and exoglucanase are used, which show a different temperature optimum. If model-based temperature control is applied in this case, enzyme-specific temperature gradients can be operated, reducing the consumption of enzymes and significantly increasing the yield of the desired product [36].

Table 2 lists common control variables (e.g. temperature, $\mathrm{pH}$-value or dissolved oxygen (DO)) of bioprocesses with their most used control strategies.

Table 2 Control strategies for key variables in bioprocesses

\begin{tabular}{|l|c|}
\hline Control variable & Applied control strategy \\
\hline Temperature & PI control [34], MPC [36], NMPC [37] \\
\hline pH & PI control [38] \\
\hline DO & On-Off-Feedback control [34], PID control [34], Cascade Control \\
& [38], MPC [34] \\
\hline Flow rate (Nutrient media...) & PI control [38] \\
\hline
\end{tabular}




\begin{tabular}{|l|c|}
\hline Pressure & PI control [38] \\
\hline $\begin{array}{l}\text { Concentration (Substrate, } \\
\text { Product...) }\end{array}$ & PI control [39], Fuzzy control [40], NMPC [41-43], OLFO [44-47] \\
\hline
\end{tabular}

220 Simple control tasks can be treated using conventional controllers. For more demanding 221 control tasks, such as e.g. concentration control, the use of advanced and model-based control 222 strategies such as MPC or NMPC has been suggested [34, 35, 48, 49]. The choice of suitable 223 control strategies is not only dependent on the controlled variable. If, for example, DO control 224 is considered, on-off feedback, PID control or more complex model-based control like MPC 225 are used depending on the requirements. In the subsequent sections, some advanced control 226 strategies will be described that may be developed and tuned utilising Digital Twins.

\section{$227 \quad 2.3 .1 \quad$ Advanced and model-based control strategies}

228 Advanced and model-based control strategies (AMBC) like NMPC are of great interest in the 229 case of processes with fast dynamics because these controllers reduce the response time [34]. 230 They do not operate just based on the current state of the system instead, the control action 231 is based on the calculated evolution of the system. AMBCs utilise integrated mathematical 232 process models for the prediction of future process behaviour. At the end of each sampling period, the future course of the control trajectory is optimised using a process model [34]. The control trajectory that fulfils the chosen optimisation criterion best is then applied to the real 235 process [34].

236 The use of $A M B C$ has already been investigated for different bioprocesses in several research works. For fermentations of S. cerevisiae NMPC was used to maximise the ethanol (EtOH) yield by controlling the glucose solution feed rate [42]. For the fed-batch cultivation of Chinese hamster ovary $(\mathrm{CHO})$ mammalian cells, a glucose concentration fixed set-point control was implemented and tuned to enhance product quality and reduce costs [43]. To enhance the sugar concentration in a cellulose hydrolysation process in a stirred tank reactor, NMPC was applied to control the feed rates of substrate and cellulase enzymes solutions [50].

243 Furthermore, temperature and humidity gradients of solid-state fermentation were 244 controlled by NMPC [51].

245 In all listed research works the use of $A M B C$ resulted in higher product concentrations at lower resource demands as compared to processes with conventional control strategies. 
2.3.2 Open-loop-feedback-optimal (OLFO) control strategy

248 A special form of AMBC is the open-loop-feedback-optimal (OLFO) strategy [52, 53]. The OLFO 249 controller belongs to the class of adaptive NMPCs. It consists of a process model, a model 250 parameter identification part, and an optimisation part (see Fig. 1). Model parameters are 251 estimated frequently based on available online and/or offline data. The updated model 252 parameters are passed on to the optimisation part, where process trajectories like substrate 253 feeding profiles are calculated. Several optimisation criteria, such as maximized product 254 concentrations, may be implemented in the controller. The OLFO control strategy has been 255 investigated in a receding horizon [8,53] and a moving horizon version $[45,47]$ for 256 bioprocesses.

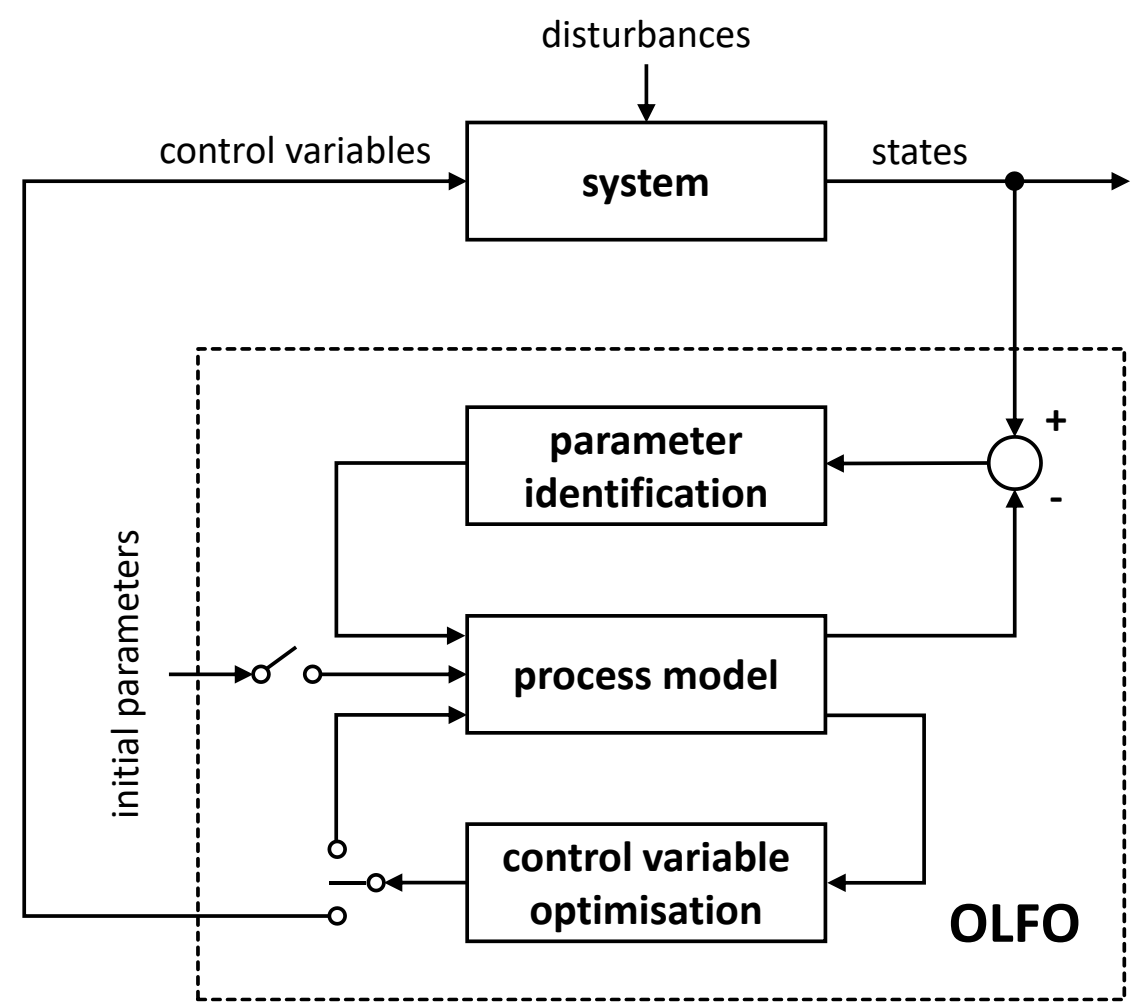

258 Fig. 1 Structure of the Open-Loop-Feedback-Optimal (OLFO) control strategy [53]

259 The OLFO strategy is particularly superior to other process control strategies if the processes 260 are in an early development phase and have not yet been optimised. The performance of the 261 OLFO algorithm for suspension cell cultures has already been demonstrated by Witte et al. 262 [53], Frahm et al. [45-47] and Li et al. [44]. In the case study presented in section 4.2 .3 the 263 application of the OLFO control strategy for fed-batch cultivation of $S$. cerevisiae will be 264 explained in more detail. 


\subsection{Digital Twin based development, realisation and optimisation of control strategies} for bioprocesses

In the early to mid-1980s, first OTSs representing "early-stage" Digital Twins were used for operator training in the chemical, nuclear and energy industries. In the late 1980s and early 1990s, the implementation of OTSs in the chemical industry evolved from pioneering work to common practice [54]. Today, Digital Twins are widely used in industries with high capital investment, complex processes and severe consequences of plant or operator failure such as the offshore oil and gas industry $[7,54,55]$. Older educational facilities for training in the oil and gas industry were based on physical copies of the control room, which are expensive and no longer needed [54]. Almost simultaneously with the first appearance of Digital Twins in the chemical industry, they were used as a tool for control strategy development [54]. In the beginning, these were relatively simple control engineering tasks, but they became more complex with the advancing development of Digital Twins [54, 55].

Dudley et al. (2008) [7] described the use of a Digital Twin of a pebble bed modular reactor plant for the development and testing of control strategies before using them on the real plant. He et al. (2019) [4] described the use of a Digital Twin for the Tennessee Eastman benchmark process. Effectiveness and performance of the Digital Twin in the development of control strategies were demonstrated in the presence of realistic fault scenarios. Three types of process faults, i.e., sensor faults, actuator faults and process disturbances were investigated and the corresponding fault size and temporal behaviour were discussed. All simulation studies and numerical results indicated that the proposed configurations are valid for safe operations in the event of a process fault. Zhang et al. (2019) [6] described the use of a Digital Twin for carbon emission reduction in intelligent manufacturing. Here, the plants' carbon emission is predicted by the Digital Twin model. A carbon emission control strategy was then optimised utilising the Digital Twin, to minimise exhaust gas emissions.

Compared to chemical processes, the application of Digital Twins for bioprocesses is still in its infancy. Thoroughness is required for modelling bioprocesses since a wide variety of parallel reactions take place at the same time. Even small changes of key process variables, such as $\mathrm{pH}$ or temperature, may have an immense influence on the kinetics [33].

Pörtner et al. (2011) used an "early-stage" Digital Twin for the optimisation of process control strategies for mammalian cell cultivations [56]. The developed bioprocess simulator is a digital 
replica of the cultivation of mammalian cell lines in a small scale STR. The bioprocess simulator was used to simulate the impact of various constant feed rates of glucose and glutamine during fed-batch on cell density and antibody concentration of a mammalian cell line. The feed rates were determined by design of experiments (DoE) methods. By using the bioprocess simulator, the cultivation process could be optimised in a considerably shorter time and fewer experiments compared to process control optimisation on the real process.

302 In a contribution by Hass et al. [17] the utilisation of an industrial biotechnology OTS was 303 presented. Control strategies that were developed using a new bioethanol plant OTS illustrated the potential for enhanced resource efficiency and reduced energy consumption. According to the authors, the potential savings in raw materials have a direct impact on the long-term profitability of the bioethanol plant and enables a reduction of operating costs. By using the OTS, the time course and dynamics of the entire plant could be analysed and subsequently optimised using new process control strategies. Performing such a study on a real plant would have been overly complex and expensive, if not impossible.

\section{Digital Twins as training and educational tools}

311 Digital Twins or 'Digital Twin-like' simulators may also be used in industry to train reactor and plant operators and in academia to educate future control and process engineers. In this context, Digital Twins are usually referred to as OTSs [9-11, 57].

OTSs became increasingly popular since the mid-twentieth century, for the use in various sectors, including the chemical and related industries $[10,54]$. The reason was the increasing complexity of process engineering plants with sophisticated automation and process control strategies placing enormous demands on the skills of the process operators $[10,54]$. Several papers were published reviewing the development and use of OTSs in the chemical process industry $[54,58,59]$.

OTSs offer the possibility to train future reactor operators and bioprocess engineers in a very 321 practical way without carrying out the real process. Even actions to compensate process malfunctions may be trained safely. Impairments on ongoing production processes due to training are avoided. OTSs can be described as "early-stage" Digital Twins.

324 The development and use of OTSs particularly for bioprocesses are beginning to attract 325 increasing academic interest [10]. Several research groups have investigated the applications 
328 the training experience of students and to increase plant operators skills in handling complex

329 bioprocesses $[13,14,16,60,61]$.

330 Table 3 gives an overview of already existing OTSs for bioprocesses.

331 Table 3 OTS applications for bioprocesses and biorefineries [10]

\begin{tabular}{|c|c|c|c|}
\hline Application & Development tools & Validation & Reference \\
\hline $\begin{array}{l}\text { Conceptual design of } 2 \text {-step } \\
\text { biodiesel synthesis process } \\
\text { (theoretical } 120,000 \text { t per year } \\
\text { capacity biorefinery) }\end{array}$ & $\begin{array}{l}\text { Aspen Plus Dynamics } \\
\text { Aspen OTS Framework }\end{array}$ & Unknown & $\begin{array}{l}\text { Ahmad et } \\
\text { al. [62] }\end{array}$ \\
\hline $\begin{array}{l}30 \mathrm{~L} \text { jacketed batch reactor } \\
\text { hydrodynamic and thermal } \\
\text { behaviour parameterisation }\end{array}$ & Unisim Design & $\begin{array}{l}\text { Simulated temperature } \\
\text { profiles compared with } \\
\text { laboratory reactor } \\
\text { temperature } \\
\text { measurements }\end{array}$ & $\begin{array}{l}\text { Balaton et } \\
\text { al. [63] }\end{array}$ \\
\hline $\begin{array}{l}\text { Anaerobic biogas production in a } \\
10 \mathrm{~L} \text { laboratory reactor }\end{array}$ & $\begin{array}{l}\text { FORTRAN (biological and } \\
\text { physicochemical sub- } \\
\text { models) } \\
\text { WinErs (reactor and plant } \\
\text { sub-models, plus } \\
\text { automation, process } \\
\text { control and GUI) }\end{array}$ & $\begin{array}{l}\text { Experimental data from } \\
\text { literature validated with } \\
\text { simulation results }\end{array}$ & $\begin{array}{l}\text { Blesgen and } \\
\text { Hass [16] }\end{array}$ \\
\hline $\begin{array}{l}\text { Bioethanol production from } S \text {. } \\
\text { cerevisiae ( } 15 \mathrm{~L} \text { STR) and Green } \\
\text { Fluorescence Protein production } \\
\text { using } E \text {. coli ( } 6 \mathrm{~L} \text { fed-batch } \\
\text { bioreactor) }\end{array}$ & $\begin{array}{l}\text { Biological and } \\
\text { physicochemical models } \\
\text { integrated into WinErs as } \\
\text { Dynamic Link Libraries } \\
\text { (DLLs) }\end{array}$ & $\begin{array}{l}\text { Substrate consumption, } \\
\text { product formation and } \\
\text { biomass yields were } \\
\text { compared between } \\
\text { laboratory reactor and } \\
\text { simulator runs }\end{array}$ & $\begin{array}{l}\text { Gerlach et } \\
\text { al. [57] }\end{array}$ \\
\hline $\begin{array}{l}\text { Large-scale commercial } \\
\text { bioethanol process (Reactors } \\
\text { ranging in size from } 30,000 \mathrm{~L} \text { to } \\
280,000 \mathrm{~L} \text { ) }\end{array}$ & $\begin{array}{l}\text { Process models written in } \\
\text { C++ were implemented as } \\
\text { DLLs in WinErs }\end{array}$ & $\begin{array}{l}\text { Model validation not } \\
\text { presented }\end{array}$ & $\begin{array}{l}\text { Gerlach et } \\
\text { al. [14] }\end{array}$ \\
\hline $\begin{array}{l}\text { Integrated cultivation and } \\
\text { homogenisation for recombinant } \\
\text { protein production in a } 10 \mathrm{LSTR}\end{array}$ & $\begin{array}{l}\text { Process models written in } \\
\text { C++ were implemented as } \\
\text { DLLs in WinErs }\end{array}$ & $\begin{array}{l}\text { Substrate consumption, } \\
\text { product formation and } \\
\text { biomass yields were } \\
\text { compared between } \\
\text { laboratory reactor and } \\
\text { simulator runs }\end{array}$ & $\begin{array}{l}\text { Gerlach et } \\
\text { al. [64] }\end{array}$ \\
\hline $\begin{array}{l}\text { Integrated wastewater } \\
\text { biodegradation and membrane } \\
\text { filtration in a } 10 \mathrm{~L} \text { submerged } \\
\text { membrane bioreactor (SMBR) }\end{array}$ & $\begin{array}{l}\text { The biological model was } \\
\text { written and implemented in } \\
\text { Pascal, while process } \\
\text { automation and GUI were } \\
\text { developed using Delphi } \\
2009\end{array}$ & $\begin{array}{l}\text { Experimental data from } \\
\text { literature validated with } \\
\text { simulation runs }\end{array}$ & $\begin{array}{l}\text { González } \\
\text { Hernández } \\
\text { et al. [60] }\end{array}$ \\
\hline $\begin{array}{l}\text { Describes the development of a } \\
\text { coding framework combined with } \\
\text { a commercial process control }\end{array}$ & $\begin{array}{l}\text { eStIM coding framework } \\
\text { used for biological and } \\
\text { process model }\end{array}$ & $\begin{array}{l}\text { Experimental data from } S \text {. } \\
\text { cerevisiae production }\end{array}$ & $\begin{array}{l}\text { Hass et al. } \\
{[65]}\end{array}$ \\
\hline
\end{tabular}




\begin{tabular}{|l|l|l|l|}
\hline $\begin{array}{l}\text { software for rapid process model } \\
\text { development in chemical and } \\
\text { biochemical engineering }\end{array}$ & $\begin{array}{l}\text { development and WinErs is } \\
\text { used for automation and } \\
\text { process control }\end{array}$ & $\begin{array}{l}\text { compared with } \\
\text { simulation results }\end{array}$ & Hass et al. \\
\hline $\begin{array}{l}\text { Bioethanol production, crossflow } \\
\text { filtration and rectification column } \\
\begin{array}{l}15 \mathrm{~L} \text { laboratory bioreactors used } \\
\text { for EtOH production) }\end{array}\end{array}$ & $\begin{array}{l}\text { Process models written in } \\
\text { C++ were implemented as } \\
\text { DLLs in WinErs. GRAFCET } \\
\text { used for developing } \\
\text { automation sequences }\end{array}$ & $\begin{array}{l}\text { Laboratory fermenter, } \\
\text { membrane filtration unit } \\
\text { and distillation runs were } \\
\text { used to validate simulator } \\
\text { runs }\end{array}$ & [17] \\
$\begin{array}{l}\text { Mammalian cell line cultivation } \\
\text { with the production of antibodies } \\
\text { in } 2 \text { L laboratory bioreactors }\end{array}$ & $\begin{array}{l}\text { Process models written in } \\
\text { FORTRAN were } \\
\text { implemented as DLLs in } \\
\text { WinErs }\end{array}$ & $\begin{array}{l}\text { Experimental data from } \\
\text { mammalian cell line } \\
\text { cultivation compared } \\
\text { with simulation results }\end{array}$ & Pörtner et \\
\hline
\end{tabular}

332 Hass et al. [17] developed one of the earliest OTSs for a complex biorefinery process. OTSs 333 were created for the bioethanol fermentation and the distillation process. Also, a separate 334 biomass power plant training simulator was developed. The mathematical process models 335 were created and implemented using the FORTRAN programming language [65]. The process control software WinErs [20] was used to link process control and the simulation models. PCS-

337 like GUls were developed to obtain full operator training simulators. Functions were 338 implemented to simulate the processes at different speeds depending on the desired training target. The different OTSs were designed for the training of students as well as industrial operators in the handling of biorefineries and biomass power plants. Encouraging training 341 outcomes were reported $[10,17]$.

342 A research project by Gerlach et al. [61] presented an OTS for the training of bioengineering 343 students and plant operators on the operational procedures and production skills required in 344 recombinant protein production processes. To enable the model to accurately represent the complex relations of factors in a recombinant protein production process, the authors outlined that several metabolic interactions affecting biomass yield, productivity and cellular 347 viability need to be mapped in the OTS model. To maintain numerical efficiency, a trade-off between model complexity and accuracy had to be found by capturing the most important metabolic processes in the OTS model, without the model being cumbersome and numerically 350 difficult to calculate. The effectiveness of OTS training for the education of bioengineering students was evaluated with promising results $[10,61]$.

352 Another possible application of OTSs is their use for training in the context of control 353 engineering. Currently, training in control engineering is frequently theoretical and abstract, 354 since investigations of different control strategy behaviour in real processes are difficult, time and cost-intensive and the number of available plants for training is limited. With the help of 
Digital Twins or other simulation tools, a wide variety of control strategies may be investigated

357 in a short time and their impact on bioprocess performance can be demonstrated. In future, 358 applications of OTSs will become even more diverse. New control strategies may be tested 359 first on the OTSs. This guarantees safe operation of the real plant. Furthermore, full plant 360 process control and operation strategies may be developed and optimised based on OTSs or 361 Digital Twins.

\section{Case Study}

363 The objective of this case study, which is based on a work of Appl et al. [8], is to demonstrate 364 the methodology and advantages of Digital Twins for the development of bioprocess control strategies using a fed-batch cultivation of S. cerevisiae as an illustrative example. Two process control strategies (respiratory quotient (RQ) feedback control and OLFO control) were developed and optimised using the "early-stage" Digital Twin "Simultaneous saccharification and fermentation simulator" (SSF-BC-Simulator). The target for both control strategies was to maximise the dry biomass concentration (S. cerevisiae) in a cultivation time of $48 \mathrm{~h}$.

\subsection{Digital Twin "SSF-BC-Simulator"}

371 The Digital Twin "SSF-BC-Simulator" is a further development of the "BioProzessTrainer" [33, 37266 ]. It is used to train bioengineering students for the operation of bioprocesses as well as a 373 control strategy development tool.

374 The Digital Twin can map the starch hydrolysis, the cultivation of S. cerevisiae and the whole375 cell biocatalysis of ethyl (S)-3-hydroxybutyrate from ethyl acetate in a small scale STR (Biostat 376 C, 20 L, B. Braun). The development of the "SSF-BC Simulator" was carried out using the 377 procedure described in section 2.2. The integrated dynamic mathematical model was written 378 in C++ and was implemented in WinErs $[20,65]$. Using the Digital Twin, it is possible to 379 accelerate the simulation of the bioprocesses up to 100 -fold. The Digital Twin can be 380 monitored and operated via the GUI shown in Fig. 2. 


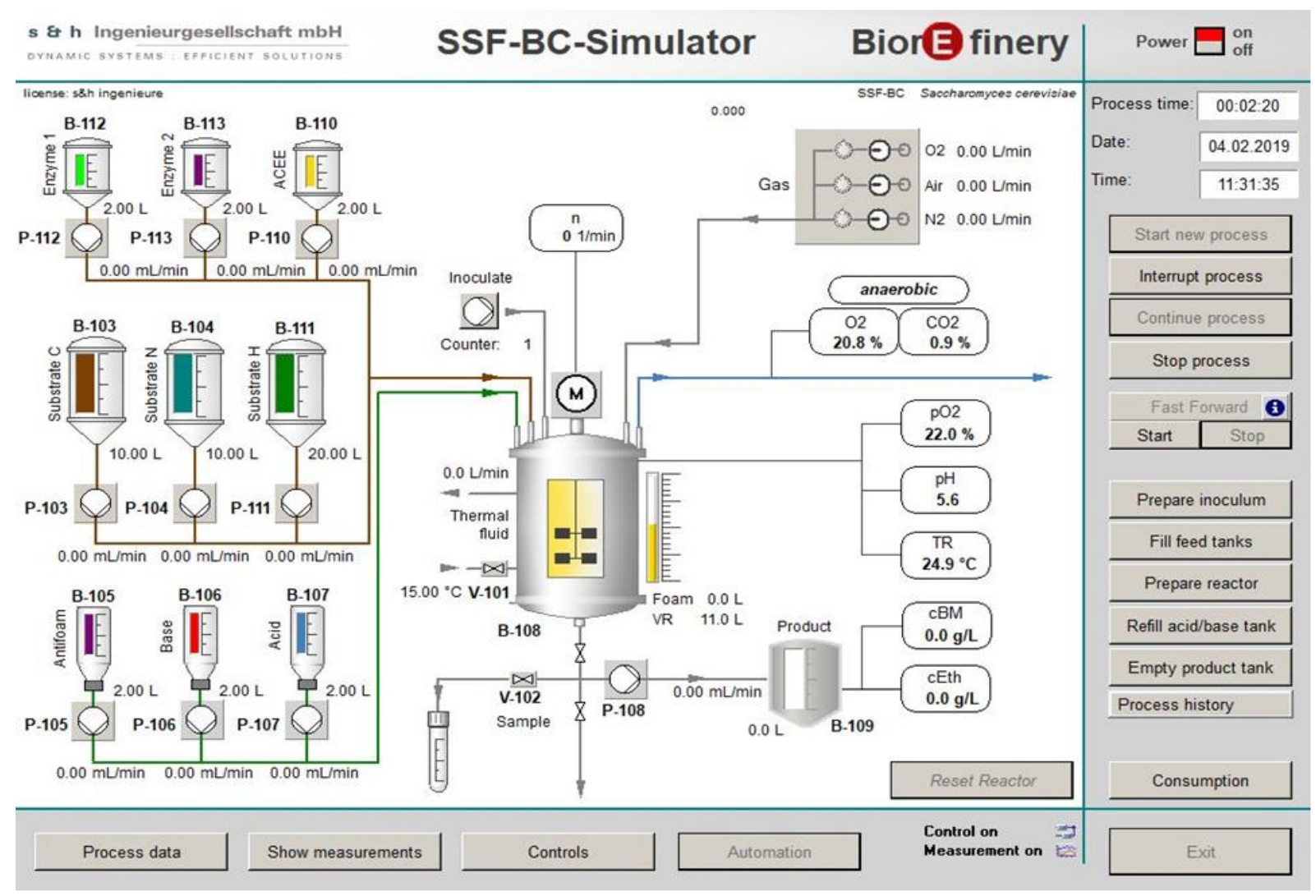

Fig. 2 GUI of the early stage Digital Twin "SSF-BC-Simulator" [20], with illustrations e.g. STR, tanks, pumps or sampling vessels that represent the real process, display windows e.g. temperature, $\mathrm{pH}$ value or DO to monitor the virtual process and buttons to set e.g. simulation speed, start conditions or stirrer speed

The GUI in Fig. 2 presents the process equipment (e.g. reactor, feed tanks...) as well as all measured value displays (e.g. temperature, $\mathrm{pH}$-value, DO...) and all essential functions of the control system (e.g. temperature or DO control) to the user of the Digital Twin. Behind each measured value display or control button, sub-models represent the real measuring or control instrument. The reactor properties and the biological process are mapped in the dynamic mathematical model of the Digital Twin. The GUI is part of the control and automation model within the Digital Twin. To use the Digital Twin for the development, optimisation and realisation of control strategies, it is therefore important that the GUI corresponds to the PCS of the real process with high similarity.

\subsubsection{Parametrisation of the Digital Twin "SSF-BC-Simulator"}

For the parameterisation of the dynamic mathematical process model implemented in the Digital Twin "SSF-BC-Simulator", a variety of parameterisation experiments were carried out, using batch and fed-batch cultivations. 
399 The procedure of model parameterisation will be illustrated using a dataset from a laboratory 400 experiment where an aerobic fed-batch cultivation was carried out in a small scale STR (Biostat $401 \mathrm{C}, 20 \mathrm{~L}, \mathrm{~B}$. Braun). The temperature was controlled at $30^{\circ} \mathrm{C}$, the $\mathrm{pH}$ value at 4.5 and the $\mathrm{DO}$ at $40210 \%$. At the beginning of the cultivation, a nutrient medium was supplied in the STR (Batch 403 medium). After the batch phase of the cultivation, a fed-batch nutrient medium was fed to 404 the STR (see Table 4).

405 Table 4 Nutrient media composition

\begin{tabular}{|l|c|c|}
\hline Component & Batch medium & Fed-batch medium \\
\hline Glucose & $5.0 \mathrm{~g} \mathrm{~L}^{-1}$ & $300 \mathrm{~g} \mathrm{~L}^{-1}$ \\
\hline Yeast extract & $0.6 \mathrm{~g} \mathrm{~L}^{-1}$ & $40 \mathrm{~g} \mathrm{~L}^{-1}$ \\
\hline Peptone from soy & $0.6 \mathrm{~g} \mathrm{~L}^{-1}$ & $40 \mathrm{~g} \mathrm{~L}^{-1}$ \\
\hline Ammonium sulphate & $0.6 \mathrm{~g} \mathrm{~L}^{-1}$ & $40 \mathrm{~g} \mathrm{~L}^{-1}$ \\
\hline
\end{tabular}

406 During the cultivation process, the following state variables required for process monitoring 407 and process control were measured (see Table 5).

408 Table 5 Measured state variables during the parametrisation experiment

\begin{tabular}{|l|c|c|}
\hline Measured state variable & Abbreviation & Unit \\
\hline Substrate (glucose) concentration & $\mathrm{S}$ & $\mathrm{g} \mathrm{L}^{-1}$ \\
\hline Product (EtOH) concentration & $\mathrm{P}$ & $\mathrm{g} \mathrm{L}^{-1}$ \\
\hline Dry biomass (S. cerevisiae) concentration & $\mathrm{X}$ & $\mathrm{g} \mathrm{L}^{-1}$ \\
\hline Fed-batch medium feed rate & Feed & $\mathrm{ml} \mathrm{min}^{-1}$ \\
\hline Oxygen in the exhaust gas & $\mathrm{O}_{2}$ & $\%$ \\
\hline Carbon dioxide in the exhaust gas & $\mathrm{CO}_{2}$ & $\%$ \\
\hline
\end{tabular}

409 After the experiment was carried out, the model of the Digital Twin "SSF-BC-Simulator" was 410 parameterised using the Nelder-Mead simplex algorithm, written in R [67], to adjust the 411 values of selected parameters to match the simulated with the measured data satisfactorily.

412 Fig. 3 and Fig. 4 present the measured state variables of the fed-batch S. cerevisiae cultivation 413 in a small scale STR compared to the simulated time courses of the Digital Twin (after 414 parameterisation). 


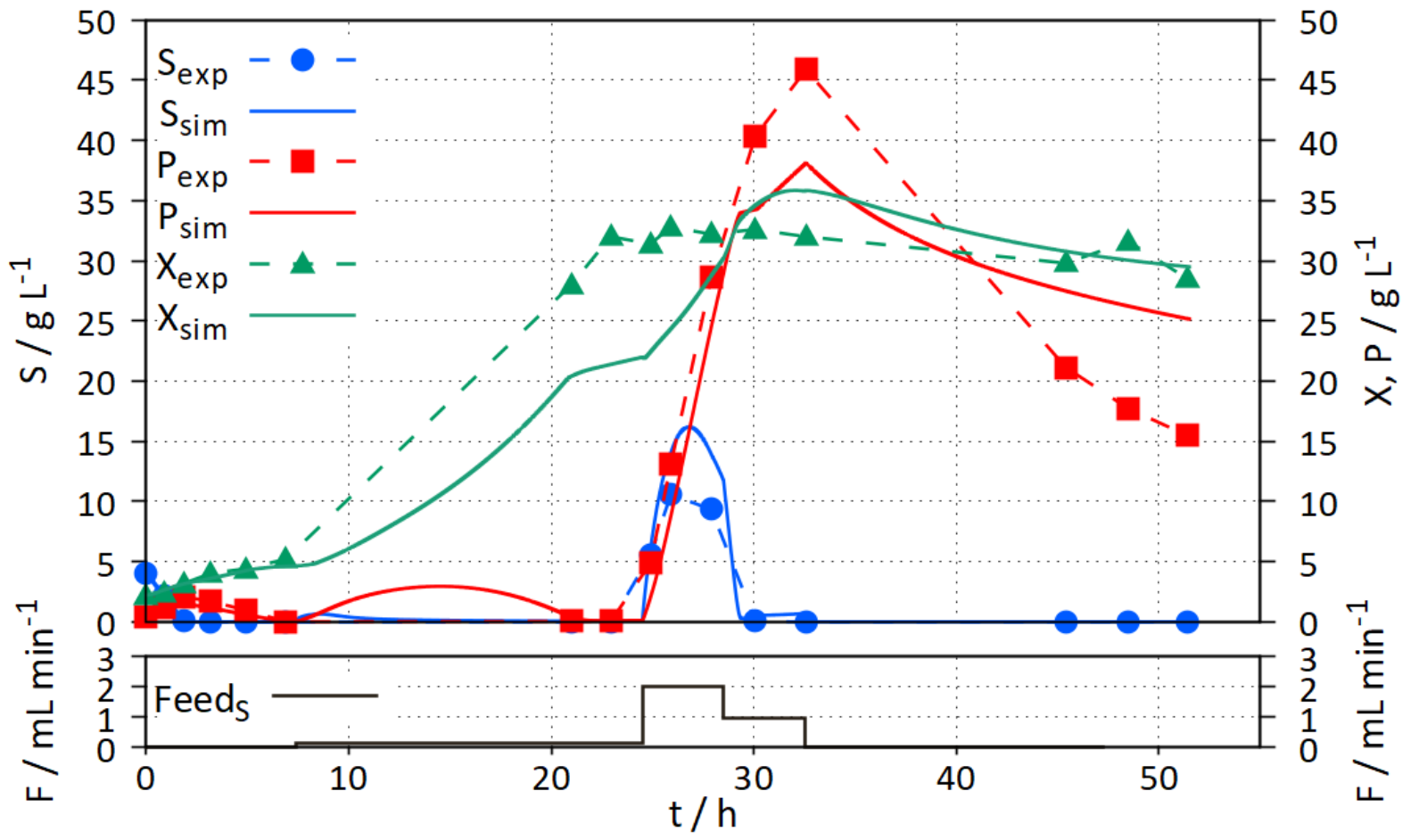

Fig. 3 Comparison of measured data (exp) from a small scale STR with simulation results (sim), S: substrate (glucose) P: product (EtOH), X: dry biomass concentration (S. cerevisiae). The bottom figure 418 shows substrate feed profile.

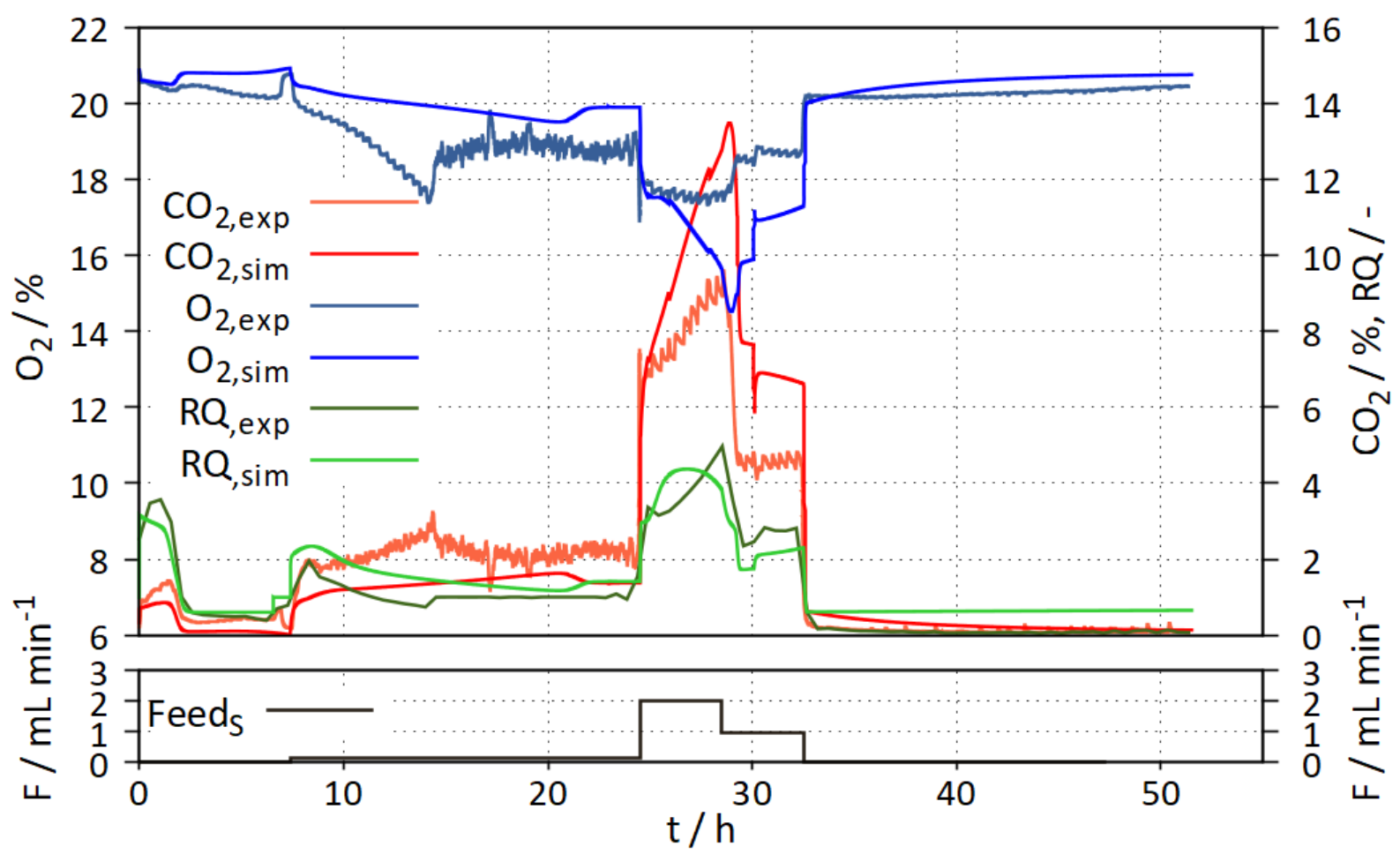

Fig. 4 Comparison of measured exhaust gas data $\left(\mathrm{CO}_{2}, \mathrm{O}_{2}\right)$ and calculated $\mathrm{RQ}$ values from a small

421 scale STR experiment (exp) with simulation results (sim). The bottom figure shows substrate feed 422 profile.

423 Fig. 3 shows that in the batch phase of the experiment $(0-7 \mathrm{~h})$, glucose was consumed. Ethanol 424 (EtOH) was formed, which was subsequently metabolised again (diauxic growth). The biomass 
density shows a slight increase during the batch phase. After the substrate feed has been activated (7-25 h), the dry biomass concentration increases to a value of more than $30 \mathrm{~g} \mathrm{~L}^{-1}$. At a processing time of $25 \mathrm{~h}$, the substrate feed was increased by a factor of almost 10, which resulted in an increase of the glucose concentration to more than $10 \mathrm{~g} \mathrm{~L}^{-1}$. An increase in the ethanol concentration to more than $45 \mathrm{~g} \mathrm{~L}^{-1}$ was observed, due to the Crabtree effect. The high ethanol concentration inhibited the growth of $S$. cerevisiae and the dry biomass concentration stagnated at a level of $30 \mathrm{~g} \mathrm{~L}^{-1}$. After the substrate feed has been reduced, the glucose concentration decreased to nearly $0 \mathrm{~g} \mathrm{~L}^{-1}$, followed by ethanol consumption down to a concentration of $15 \mathrm{~g} \mathrm{~L}^{-1}$. However, after $22 \mathrm{~h}$ of process time, no further biomass growth could be observed.

In Fig. 4 it can be seen that these effects are also reflected in the measured exhaust gas values. Special attention should be paid to the course of the RQ value (see section 4.2.2 for details). At the beginning of the batch phase $(0-3 \mathrm{~h})$, the $R Q$ rises to a value above 3 , indicating ethanol formation. After the initial phase, the RQ value dropped below 1, now indicating ethanol consumption. At the beginning of substrate feeding, a parallel increase in $\mathrm{CO}_{2}$ formation and $\mathrm{O}_{2}$ consumption can be observed, thus indicating good aerobic growth of $\mathrm{S}$. cerevisiae. During this phase, the RQ settled at a value around 1.0. From a processing time of $25 \mathrm{~h}$, the substrate feed was strongly increased. In this period a large increase in $\mathrm{CO}_{2}$ formation can be seen, however, the consumption of $\mathrm{O}_{2}$ increases only slightly, leading to an $\mathrm{RQ}$ value of above 3 . This high RQ value again indicates the formation of ethanol, which is confirmed by the offline ethanol concentration measurements. At the end of the cultivation, both the formation of $\mathrm{CO}_{2}$ and the $\mathrm{O}_{2}$ consumption value dropped close to zero, indicating weak metabolism and poor growth. These observations confirm, that particularly the RQ-value is a valuable indicator for various metabolic effects as also stated previously [68].

\subsubsection{Digital Twin "SSF-BC-Simulator" for the development of control strategies}

To ensure that the Digital Twin is suitable for the development of control strategies for the cultivation of S. cerevisiae, it must be able to represent the time courses of the experimental data described in Fig. 3 and Fig. 4. These time courses do not have to be simulated exactly, but the associated effects must be reproduced. For the development of the RQ feedback control strategy utilising the Digital Twin, it is important that exhaust gas measurements, RQ value time course and associated effects can be mapped. For the development of the OLFO 
controller with the Digital Twin, it is necessary to simulate the course of the concentrations of substrate, product and biomass and the corresponding effects.

Fig. 3 shows that the time course of the measured variables can be mapped by the Digital Twin with a high agreement. Also, ethanol formation due to the Crabtree effect can be represented by the Digital Twin (0-3 $\mathrm{h}$ and 25-33 h). It is also clearly recognisable that high ethanol concentrations inhibit the growth of the cultivated S. cerevisiae strain in the simulation (30$52 \mathrm{~h})$.

Fig. 4 illustrates that the time courses of the measured exhaust gas values can almost be exactly reproduced by the Digital Twin. Also, in the simulation, an increase in the RQ value occurs if ethanol is formed due to the Crabtree effect (0-3 $\mathrm{h}$ and 25-33 h). Furthermore, at the end of the simulated cultivation, almost no $\mathrm{CO}_{2}$ is formed or $\mathrm{O}_{2}$ is consumed, corresponding to a low growth rate.

The results presented in Fig. 3 and Fig. 4 illustrate the high potential of the Digital Twin for the development of an RQ feedback control strategy and an OLFO strategy for the cultivation of S. cerevisiae. In the presented study, the control target was to maximise the dry biomass concentration (S. cerevisiae). To achieve this target, it is important to dose the substrate feed in such a way that the cells are sufficiently supplied with glucose. However, overdosing substrate may lead to ethanol formation (Crabtree effect), which then might cause growth inhibition.

\subsection{Digital Twin based development of control strategies for the cultivation of $S$. cerevisiae}

During process control strategy development, the different strategies were first applied to the "SSF-BC-Simulator". Simulations with varying controller designs and tunings were then carried out on the Digital Twin until the desired controller performance was achieved. Afterwards, the experimental validation of the control strategies on the real plant took place. If the control result was still unsatisfactory, further controller improvements were tested using the Digital Twin, before validating the controllers on a real cultivation process. By using the Digital Twin, many complex experiments in the STR with elaborate preparation, execution and analysis could be avoided in the development of the control strategies, which resulted in a resourcesaving of over $50 \%$. Also, the acceleration mode of the Digital Twin offered a significant reduction in development time. 
To realise a smooth transfer of the control strategies between the "twins", the Digital Twin and the small scale STR were connected to the identical process control system WinErs [20], in which also the controllers were implemented (see Fig. 5).

\section{Stirred Tank Reactor (STR)}



or

Digital Twin "SSF-BC-Simulator"

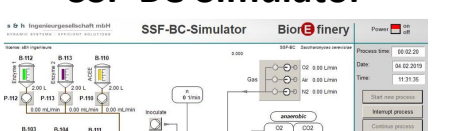

|I] II

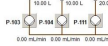

调 i调
491

492

493

494

495

496

497

498

499

500

501

502

503

504

505

\section{Process Control System}

(PCS)

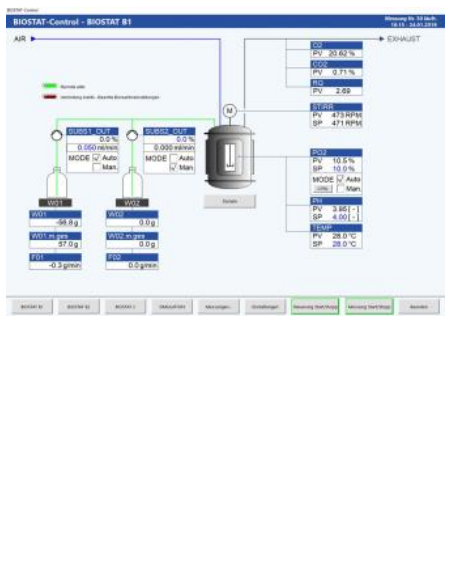

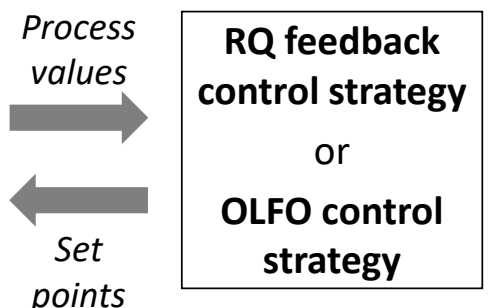

Fig. 5 Linking of STR, Digital Twin and PCS (with associated control strategies) in the Digital Twin based development of control strategies for the cultivation of $S$. cerevisiae

Since both, the real STR and the Digital Twin were connected to the identical PCS, the control strategies could be quickly and variably applied and transferred to the real and simulated process. Both the PCS and the control strategies (RQ feedback and OLFO) were realised in separate coupled WinErs projects, which leads to high compatibility.

\subsubsection{Development of respiratory quotient (RQ) feedback control for the cultivation of $S$.} cerevisiae

The RQ feedback control strategy is an established soft sensor control strategy used for fedbatch cultivations of S. cerevisiae [68]. To ensure optimal growth of S. cerevisiae the RQ should be kept close to a value of 1.0. For the determination of the RQ value, the composition of the exhaust gas from the reactor during the cultivation is measured using a gas analyser (SIDOR, Sick). The RQ value can be calculated from the measured mole fractions of $\mathrm{O}_{2}$ and $\mathrm{CO}_{2}$ in the supply air and the exhaust gas (eq. 1-3),

$$
y_{i, 0}=1-\left(y_{O_{2}, 0}+y_{C_{2}, 0}\right)
$$




$$
\begin{gathered}
y_{i, 1}=1-\left(y_{O_{2}, 1}+y_{C_{2}, 1}\right) \\
R Q=\frac{\left(y_{C O_{2}, 1} \cdot\left(\frac{y_{i, 0}}{y_{i, 1}}\right)\right)-y_{C_{2}, 0}}{y_{O_{2}, 0}-\left(y_{O_{2}, 1} \cdot \frac{y_{i, 0}}{y_{i, 1}}\right)}
\end{gathered}
$$

506 where $y_{i, 0}$ is the mole fraction of inert components in the supply air, $y_{i, 1}$ is the mole fraction of 507 inert components in the exhaust gas, $y_{O_{2}, 0}$ is the mole fraction of $\mathrm{O}_{2}$ in the supply air 508 (assumption: 0.2096), $y_{\mathrm{O}_{2}, 1}$ is the mole fraction of $\mathrm{O}_{2}$ in the exhaust gas, $y_{\mathrm{CO}_{2}, 0}$ is the mole 509 fraction of $\mathrm{CO}_{2}$ in the supply air (assumption: 0.00035 ) and $y_{\mathrm{CO}_{2}, 1}$ is the mole fraction of $\mathrm{CO}_{2}$ in 510 the exhaust gas.

511 To realise the RQ feedback control strategy a PI controller was chosen. Based on the difference 512 between the RQ value and RQ setpoint, the PI controller calculated the appropriate substrate 513 feed and transmitted it to the bioreactors digital control unit (DCU) every 5 minutes.

514 In the development process of the RQ feedback control strategy on the Digital Twin, various $515 \mathrm{RQ}$ value setpoints were tested, the controller parameters (gain, integration time) of the PI 516 controller were adjusted and the transfer intervals of the calculated substrate feed rates to 517 the DCU were varied. Furthermore, different ratios of glucose and nitrogen sources in the feed 518 medium were investigated. To achieve the predetermined control target of $50 \mathrm{~g} \mathrm{~L}^{-1}$ after a 519 processing time of $48 \mathrm{~h}$, four simulations on the Digital Twin were performed.

520 The transfer of the RQ feedback control strategy to the real process took place after 521 simulations on the Digital Twin yielded a dry biomass concentration of more than $50 \mathrm{~g} \mathrm{~L}^{-1}$ 522 within $48 \mathrm{~h}$. Then, the RQ feedback control strategy was experimentally validated on the real 523 cultivation process in the small scale STR. The results of the real RQ feedback-controlled 524 cultivation of S. cerevisiae in a small scale STR are presented in Fig. 6. 

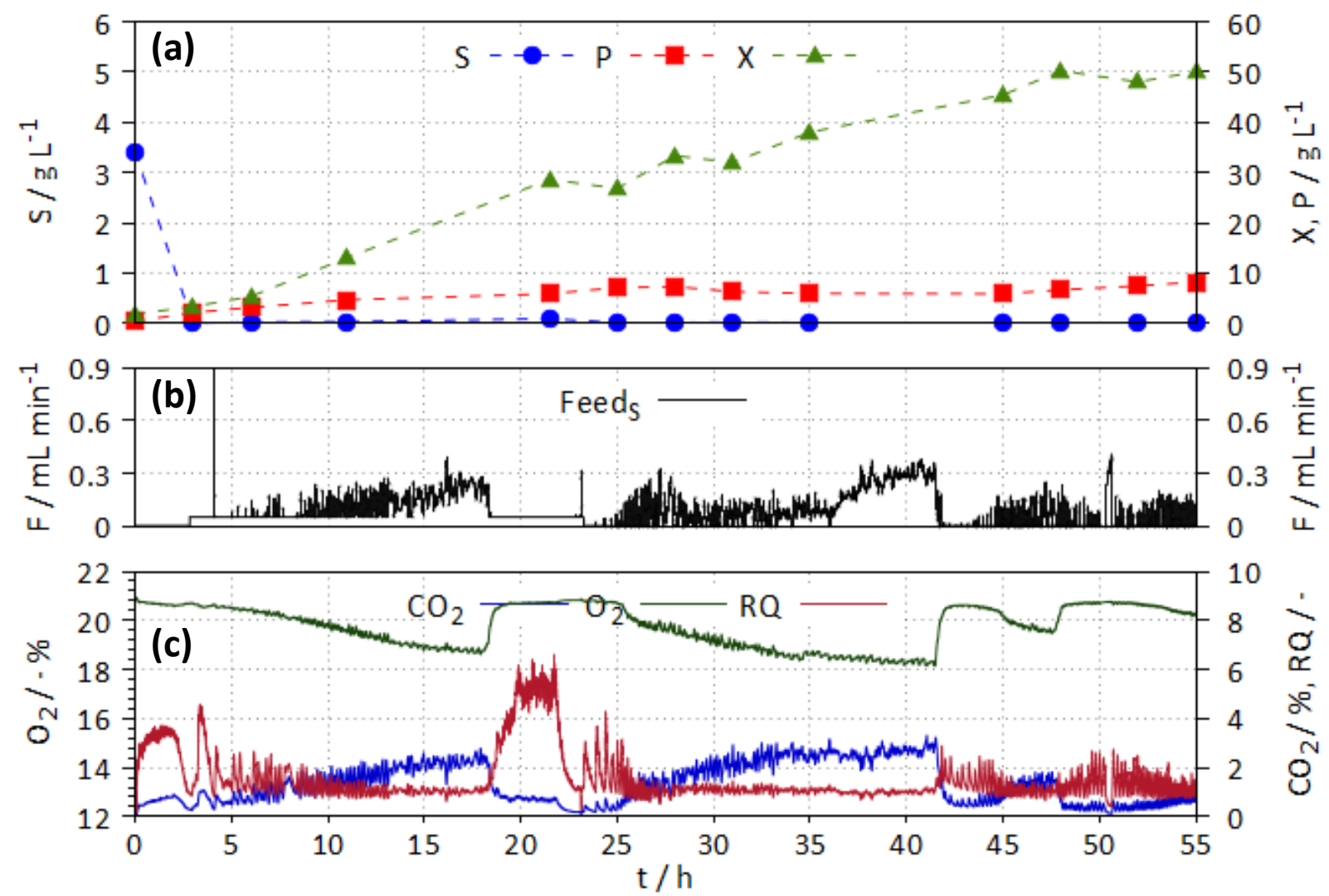

Fig. 6 Results of an RQ feedback-controlled S. cerevisiae cultivation in a STR

527 Fig. 6 (b) shows that the substrate feed (Feeds) started at 3h. At this time, the batch phase was 528 finished and the RQ Feedback controller was switched on. After that, the mean substrate feed rate increased steadily up to $18 \mathrm{~h}$. The addition of nutrient medium leads to a steady increase 530 in dry biomass concentration up to $25 \mathrm{~g} \mathrm{~L}^{-1}$ (Fig. 6 (a)). Fig. 6 (c) shows that both, $\mathrm{O}_{2}$ 531 consumption and $\mathrm{CO}_{2}$ formation, increase during the first $18 \mathrm{~h}$. The resulting $\mathrm{RQ}$ value 532 stabilises to a value close to 1.1. After a processing time of $18 \mathrm{~h}$, the RQ value increased to a 533 value of up to 6 , resulting in a substrate feed rate, controlled to the set minimum value of 0.05 $534 \mathrm{ml} \mathrm{min}{ }^{-1}$. When the substrate was depleted, the RQ value dropped below 1.1 again (approx. $53525 \mathrm{~h}$ ), the substrate feed rate started to increase. At processing times of $43 \mathrm{~h}$ and $47 \mathrm{~h}$, the 536 same effect observed at $18 \mathrm{~h}$ can be seen in an attenuated form. One explanation for the 537 sudden increase in the RQ value is the composition of the nutrient medium. Among other components, yeast extract was used as a nitrogen source, which contains high amounts of 539 both nitrogen and carbon. The fraction of residual yeast extract in the medium was rather 540 high, leading to an accumulation of carbon sources and thus to an increasing RQ value due to 541 the Crabtree effect. In the Digital Twin model, the carbon component in the nitrogen sources 542 was not considered, which is why this effect could only be recognised in the real experiment. 543 Despite this limitation of the Digital Twin model, an RQ feedback control could be developed 
544 based on the Digital twin, leading to more than $50 \mathrm{~g} \mathrm{~L}^{-1}$ dry biomass concentration in the real 545 process, with less than $10 \mathrm{~g} \mathrm{~L}^{-1}$ ethanol produced within $48 \mathrm{~h}$.

546 It took about 2 days to develop the RQ feedback control for the cultivation of S. cerevisiae on 547 the Digital Twin (simulations, controller adaptations). Real cultivation of $48 \mathrm{~h}$ in a STR, 548 including preparation and evaluation, is expected to take about 1 week. If instead of the 549 simulations on the Digital Twin, real cultivations had to be carried out during the control 550 strategy development process, the development time would have been extended to up to 3 551 weeks. Besides the significant time savings, the consumption of resources (nutrient media 552 components, energy...) was also significantly reduced due to the reduced number of real 553 cultivations.

554 555

571 During controller development using the Digital Twin, six simulations were carried out in total. 572 After each simulation, the simulated cultivation results were evaluated and the control 573 strategy was adjusted to approach the control target (50 $\mathrm{g} \mathrm{L}^{-1}$ dry biomass concentration

\subsubsection{Development of open-loop-feedback-optimal (OLFO) control for the cultivation of $S$.} cerevisiae

The principle of the OLFO control strategy has been described in section 2.3.2. The suitability of the "SSF-BC-Simulator" as a tool for the development of the OLFO control strategy for the cultivation of S. cerevisiae was illustrated in Fig. 3, section 4.1.

The core of the OLFO controller is a relatively simple mathematical model for the cultivation of S. cerevisiae, which is different from the process model within the presented Digital Twin. The controller model is limited to map the consumption of glucose and nitrogen, the growth of $S$. cerevisiae and the formation of the side product ethanol. The mathematical OLFO controller model was adapted based on either measured (real process) or simulated (Digital Twin) concentrations of substrate (glucose), product (ethanol) and biomass density ( $S$. cerevisiae). In the optimisation part of the OLFO controller, substrate feed rate trajectories were optimised at several points during the real or simulated (Digital Twin) process using the adapted mathematical process model, where the adaption was based on the data available up to the actual processing time. The substrate feed rate trajectory yielding the highest concentration of dry biomass at the end of the simulated cultivation (OLFO process model) was transferred to the PCS at each time point of model adaption and process optimisation. 

presented in Fig. 7.

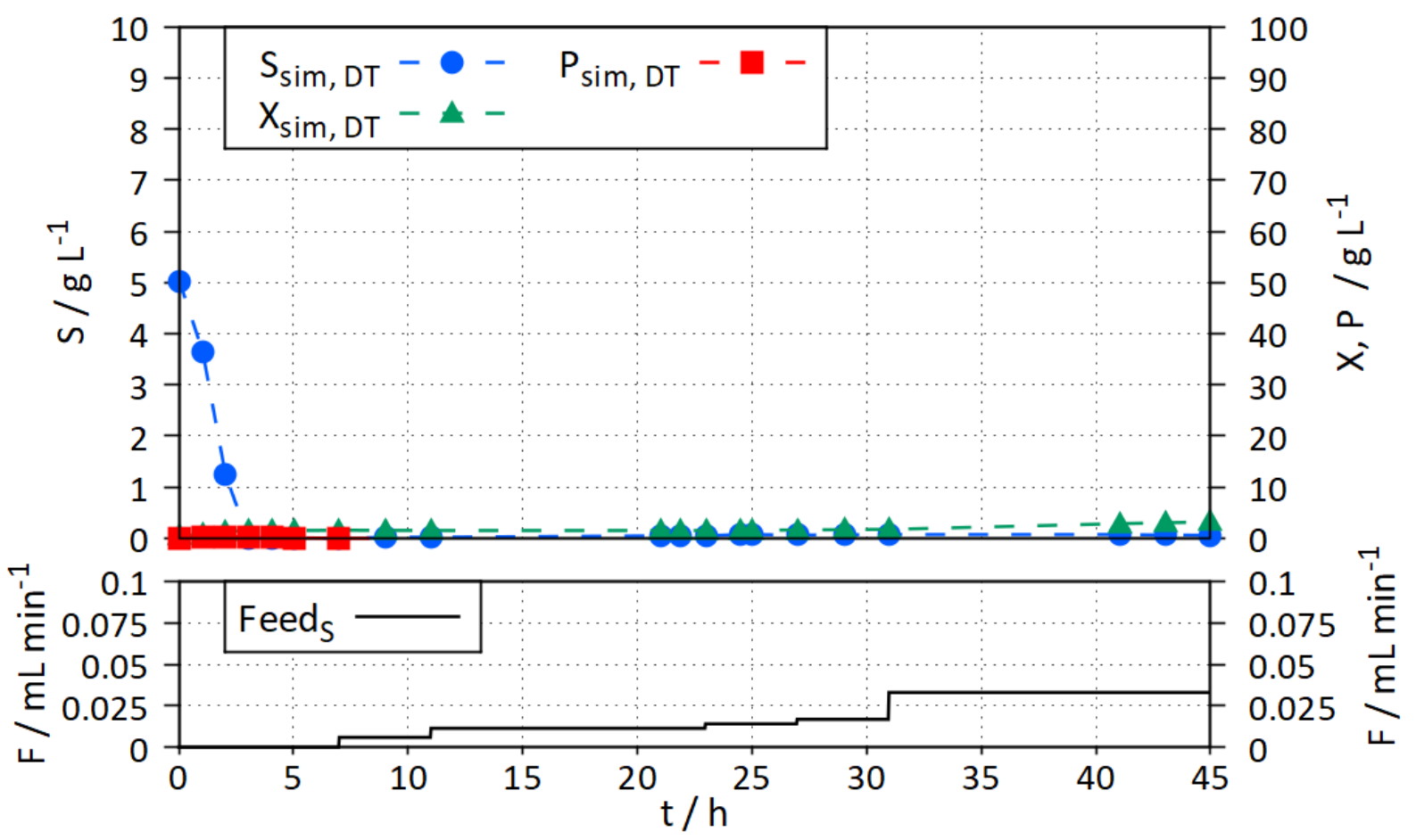

576

577

578

579

580

581

582

583

584

585

586

587

588

589

590

591

Fig. 7 Result of the first OLFO controlled simulated cultivation of S. cerevisiae using the Digital Twin "SSF-BC-Simulator"

In the first OLFO controlled Digital Twin cultivation of S. cerevisiae, only a low dry biomass concentration of $4 \mathrm{~g} \mathrm{~L}^{-1}$ could be achieved within the processing time of $48 \mathrm{~h}$, due to low substrate feed rates $\left(\max .0 .03 \mathrm{ml} \mathrm{min}^{-1}\right.$ ) determined by the OLFO controller. A detailed analysis revealed an ethanol inhibition in the mathematical process model already starting at less than $5 \mathrm{~g} \mathrm{~L}^{-1}$. Consistently, the OLFO controller calculated low substrate feed rates to avoid ethanol formation. However, the resulting low glucose concentration limited growth.

Increasing the ethanol inhibition constant in the mathematical process model to approx. $30 \mathrm{~g} \mathrm{~L}^{-1}$ led to an increase in the final simulated dry biomass concentration $\left(15 \mathrm{~g} \mathrm{~L}^{-1}\right)$. However, the set control target could not yet be achieved. Based on subsequent simulations with the Digital Twin, further controller model adjustments such as modifying the metabolic rates related to the Crabtree effect, adjustments of uptake rates, etc. were performed. The intervals for model adaptation and subsequent substrate feed optimisations were varied and different compositions of the nutrient medium were examined via simulations with the Digital Twin. 
592 In the sixth OLFO controlled cultivation simulated on the Digital Twin, the set control target 593 eventually was exceeded by reaching a final biomass density of $80 \mathrm{~g} \mathrm{~L}^{-1}$ within $48 \mathrm{~h}$ (Fig. 8) and 594 less than $10 \mathrm{~g} \mathrm{~L}^{-1}$ ethanol.

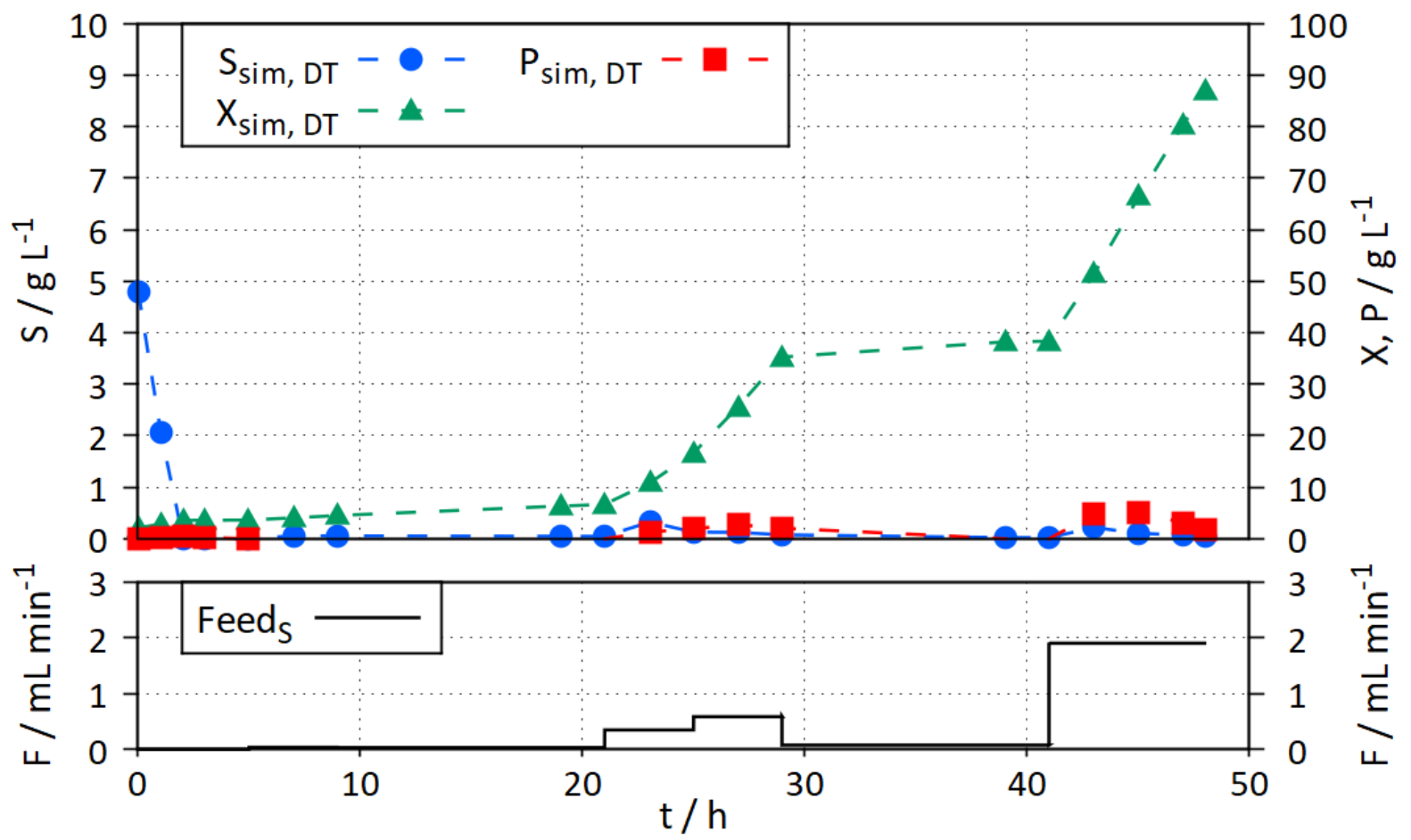

595

Fig. 8 Sixth OLFO controlled cultivation of S. cerevisiae on the Digital Twin "SSF-BC-Simulator"

597 The resulting OLFO controller (developed on the Digital Twin) was transferred to the real 598 process for experimental validation. Fig. 9 shows the results of the OLFO controlled $S$. 599 cerevisiae cultivation. 


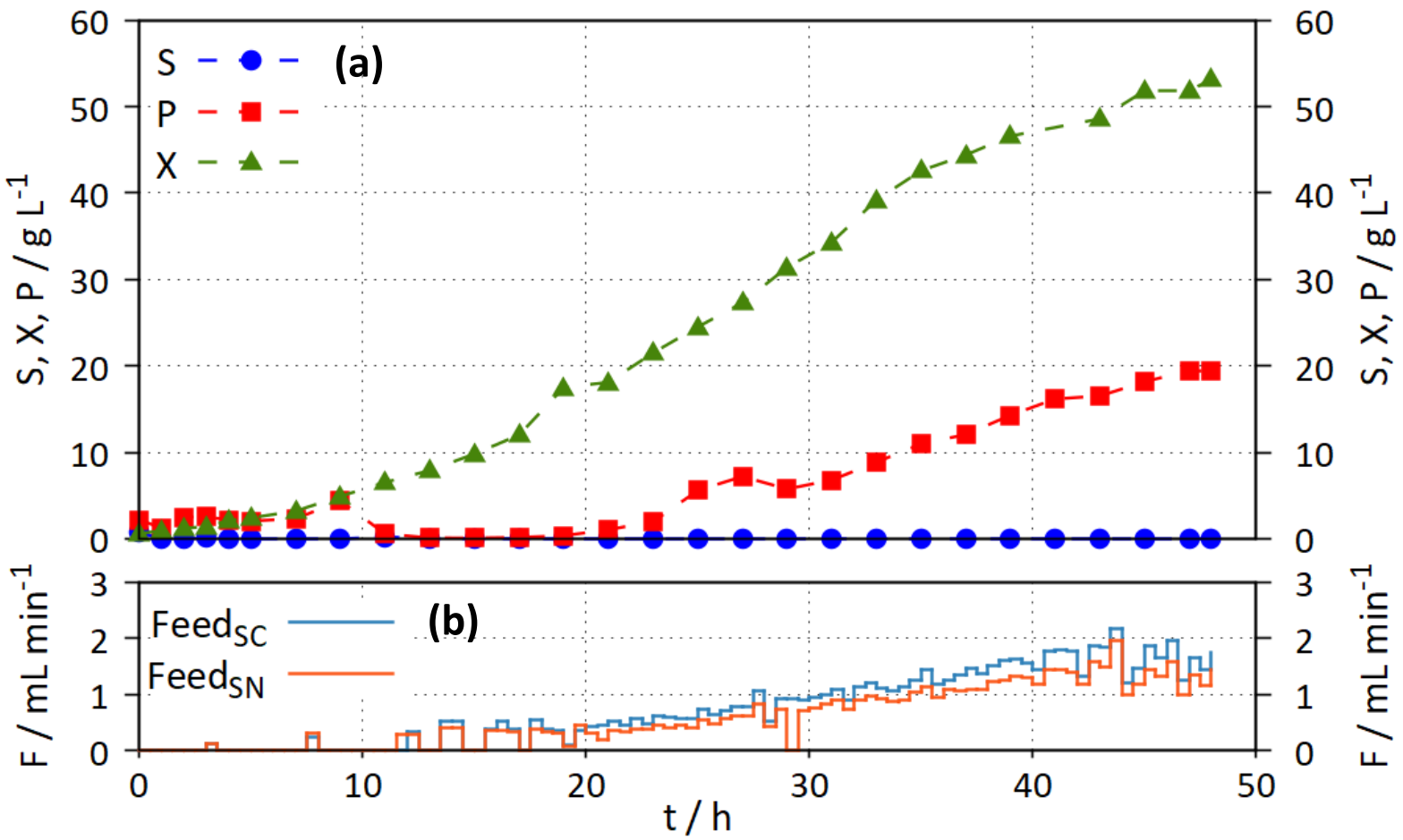

600

Fig. 9 OLFO controlled S. cerevisiae cultivation in a 20 L STR (Biostat C, B. Braun)

602 In the OLFO-controlled real cultivation, a dry biomass concentration of more than $50 \mathrm{~g} \mathrm{~L}^{-1}$ was 603 achieved within $48 \mathrm{~h}$. Both, the substrate feed rates (Fig. 9 (b)) and the dry biomass 604 concentration (Fig. 9 (a)) increase steadily over the entire process time. The ethanol 605 concentration never exceeded $20 \mathrm{~g} \mathrm{~L}^{-1}$.

606 It took about 2 weeks to develop the OLFO control for the cultivation of S. cerevisiae on the 607 Digital Twin (simulations, controller adaptations). Real cultivation of $48 \mathrm{~h}$ in a STR, including 608 preparation and evaluation, is expected to take about 1 week. If instead of the simulations on 609 the Digital Twin, real cultivations had to be carried out during the control strategy 610 development process, the development time would have been extended to up to 2 months. 611 Besides the significant time savings, the consumption of resources was also significantly 612 reduced due to the smaller number of real cultivations.

\subsubsection{Case study discussion}

614 This case study demonstrated the enormous potential of the Digital Twin "SSF-BC-Simulator" 615 to support the control strategy development and optimisation for the cultivation of $S$. cerevisiae. By utilising the Digital Twin, it was possible to effectively develop both control that 617 uses online values (RQ feedback control) and control that uses offline values (OLFO control). 618 By conducting simulations using the Digital Twin, real experiments could be avoided that 
619 would have been associated with the consumption of resources and time. By using the Digital 620 Twin, an estimated amount of resources of about $60 \%$ and time of about $50 \%$ could be saved

621 in the development process of both control strategies compared to conventional control 622 strategy development.

623 In this case study, we were able to demonstrate the beneficial utilisation of Digital Twins for 624 the development, optimisation and realisation of bioprocess control strategies. An important 625 prerequisite for the Digital Twin utilisation for control development is the validation of a high 626 accuracy in mapping the bioprocess dynamics.

627 The presented Digital Twin "SSF-BC-Simulator" is also capable of mapping the enzymatic 628 process of starch hydrolysis as well as the biocatalysis of ethyl (S)-3-hydroxybutyrate. For 629 these processes various control strategies will be developed in future, supported by the Digital 630 Twin.

\section{Conclusion and future perspectives}

632 This chapter demonstrated the enormous potential of Digital Twins or "early-stage" Digital 633 Twins as a control strategy development tool and their application to bioprocesses. The use 634 of Digital Twins enables the development of advanced controllers that increase the efficiency 635 of bioprocesses. By accelerated and parallel running simulations on the Digital Twin, the 636 development time is drastically reduced compared to conventional control strategy 637 development. In the past, production usually had to be interrupted to investigate the dynamic 638 behaviour of the bioprocessing plant under consideration, as well as the dynamics of different 639 controlled systems, which is necessary for the development of control strategies. By using Digital Twins, the production plants can remain in operation during controller development and optimisation. The presented case study demonstrates a rapid and effective controller transfer to the real plant as soon as the new controllers have been successfully developed utilising the Digital Twin. An ideal process operation not only requires well-designed and tuned controllers but also well-trained plant operators. This can be achieved using OTSs that may be considered as "early-stage Digital Twins". From the further development of OTSs, educational Digital Twins have emerged, which are characterised by the following features: 
(2) Detailed technical simulation of the reactor environment including peripheral equipment

(3) Realistic investigation of various control strategies

(4) Accelerated and resource-saving simulation (digital experimentation and training)

As new advanced bioprocessing plants are put into operation worldwide, the challenge of covering the need for suitably qualified operators to run these plants will increase. Educational Digital Twins are an effective tool to meet this challenge. In the future, simple and costeffective educational Digital Twin development tools are required to adequately handle the additional complexities present in bioprocesses.

\section{Acknowledgements}

The authors would like to thank C. Fittkau and S. Dreßler for their excellent laboratory work at Furtwangen University. We gratefully appreciate, that parts of the presented work have been funded by the German Federal Ministry of Education and Research, Innovation Alliance prot P.S.I. (FKZ: 031B0405C).

\section{References}

1. Grieves M (2016) Origins of the Digital Twin Concept: Working Paper

2. Glaessgen E, Stargel D (2012) The Digital Twin Paradigm for Future NASA and U.S. Air Force Vehicles: 22267B. https://doi.org/10.2514/6.2012-1818

3. El Saddik A (2018) Digital Twins: The Convergence of Multimedia Technologies. IEEE MultiMedia 25: 87-92. https://doi.org/10.1109/MMUL.2018.023121167

4. He R, Chen G, Dong C et al. (2019) Data-driven digital twin technology for optimized control in process systems. ISA Trans 95: 221-234. https://doi.org/10.1016/j.isatra.2019.05.011

5. Zobel-Roos S, Schmidt A, Mestmäcker F et al. (2019) Accelerating Biologics Manufacturing by Modeling or: Is Approval under the QbD and PAT Approaches Demanded by Authorities Acceptable Without a Digital-Twin? Processes 7: 94. https://doi.org/10.3390/pr7020094

6. Zhang C, Ji W (2019) Digital twin-driven carbon emission prediction and low-carbon control of intelligent manufacturing job-shop. Procedia CIRP 83: 624-629. https://doi.org/10.1016/j.procir.2019.04.095 
678 7. Dudley T, Villiers P de, Bouwer W et al. (2008) The Operator Training Simulator System 679 for the Pebble Bed Modular Reactor (PBMR) Plant. Nuclear Engineering and Design 238: 2908-2915. https://doi.org/10.1016/j.nucengdes.2007.12.028

8. Appl C, Fittkau C, Moser A et al. (2019) Adaptive, Model-Based Control of Saccharomyces cerevisiae Fed-Batch Cultivations. In: AIDIC SERVIZI SRL (ed) Book of Abstracts: Bridging Science with Technology, pp 1504-1505

9. Hass VC, Kuhnen F, Schoop K-M (2005) Rapid Design of interactive operator-training simulators for training and education. 7th World Congress of Chemical Engineering, WCCE 2005, 10th -14th July

10. Isimite J, Baganz F, Hass VC (2018) Operator training simulators for biorefineries: current position and future directions. J Chem Technol Biotechnol 93: 1529-1541. https://doi.org/10.1002/jctb.5583

11. Hass VC (2016) Operator Training Simulators for Bioreactors. In: Mandenius C-F (ed) Bioreactors: Design, Operation and Novel Applications, vol 69. Wiley, Weinheim, Germany, pp 453-486

12. Pavé A (2012) Modeling living systems: From cell to ecosystem. Environmental engineering series. ISTE Wiley, London

13. Hass VC, Knutzsch S, Gerlach I et al. (2012) Towards the Development of a Training Simulator for Biorefineries. Chemical Engineering Transactions: 247-252. https://doi.org/10.3303/CET1229042

14. Gerlach I, Hass V, Mandenius C-F (2015) Conceptual Design of an Operator Training 699 Simulator for a Bio-Ethanol Plant. Processes 3: 664-683. https://doi.org/10.3390/pr3030664

15. Blesgen A (2009) Entwicklung und Einsatz eines interaktiven Biogas-Echtzeit-Simulators. 702 Dissertation, Universität Bremen

16. Blesgen A, Hass VC (2010) Efficient Biogas Production through Process Simulation †. Energy Fuels 24: 4721-4727. https://doi.org/10.1021/ef9012483

17. Hass VC, Kuntzsch S, Schoop K-M et al. (2014) Resource Efficiency Studies using a New 706 Operator Training Simulator for a Bioethanol Plant. In: PRES 2014, 17th Conference on Process Integration, Modelling and Optimisation for Energy Saving and Pollution Reduction: PRES 2014, 23-27 August 2014, Prague, Czech Republic. AIDIC Associazione 
Italiana di Ingegneria Chimica ČSCHI Česká Společnost Chemického Inženýrství, Milano, pp 541-546

711

712

713

714

715

716

18. Honeywell (2020) UniSim Competency Suite. https://www.honeywellprocess.com/enUS/explore/products/advanced-applications/unisim/unisim-competencysuite/Pages/default.aspx. Accessed 18 Aug 2020

19. CORYS (2020) Indiss Plus ${ }^{\circledR}$. https://www.corys.com/en/indiss-plusr. Accessed 18 Aug 2020

20. Ingenieurbüro Dr.-Ing.Schoop GmbH (2018) WinErs: Process control and automation system on PC under Windows, Hamburg, Germany

21. Hass VC, Kuhnen F, Schoop K-M (2005) An environment for the development of operator training systems (OTS) from chemical engineering models. Computer Aided Chemical Engineering: 289-293. https://doi.org/10.1016/S1570-7946(05)80170-1

22. Perceptive Engineering (2020) PerceptiveAPC - Key Features and Tools. https://www.perceptiveapc.com/software/features/. Accessed 18 Aug 2020

23. DuPont Industrial Biosciences (2020) Operator Training Simulator and Training Solutions for STRATCO ${ }^{\circledR}$ Alkylation - DuPont Industrial Biosciences. http://cleantechnologies.dupont.com/technologies/stratcor/stratcor-equipmentservices/alkylation-technology-training-solutions/. Accessed 18 Aug 2020

24. Aspen Technology (2008) Aspen OTS Framework: Best-in-class technology to configure and build Operator Training Simulator applications. https://www.aspentech.com/uploadedfiles/products/templates/aspen_ots.pdf. Accessed 18 Aug 2020

25. Wood (2018) ProDyn - operator training simulator software. https://www.woodplc.com/capabilities/digital-and-technology/software,-applicationsand-analytics/prodyn-operator-training-simulator-software. Accessed 18 Aug 2020

26. NovaTech (2017) Training Simulators | NovaTech Process Control \& Optimization. https://www.novatechweb.com/process-control/training-simulators/. Accessed 18 Aug 2020

27. Outotec (2020) HSC Sim: Process Simulation Module. https://www.outotec.com/products-and-services/technologies/digital-solutions/hscchemistry/hsc-sim-process-simulation-module/. Accessed 18 Aug 2020 
28. Protomation (2019) Custom made OTS. https://protomation.com/custom-made-ots/. Accessed 18 Aug 2020

29. Siemens AG (2020) SIMIT Simulation. https://new.siemens.com/global/de/produkte/automatisierung/industriesoftware/simit.html. Accessed 18 Aug 2020

30. SimGenics (2020) SimuPACT. https://www.simgenics.com/page/simupact. Accessed 18 Aug 2020

31. Yokogawa (2020) Operator Training Simulator (OTS) which supports to acquire plant operation skills by using it with a dynamic virtual plant model. https://www.yokogawa.com/solutions/solutions/energy-management/operatortraining-simulator/. Accessed 18 Aug 2020

32. Hitzmann B, Scheper T (2018) Bioprozessanalytik und -steuerung. In: Chmiel H, Takors R, Weuster-Botz D (eds) Bioprozesstechnik. Springer Berlin Heidelberg, Berlin, Heidelberg, pp 263-294

33. Hass VC, Pörtner R (2011) Praxis der Bioprozesstechnik: Mit virtuellem Praktikum, 2. Aufl. Spektrum Akad. Verl., Heidelberg

34. Baeza JA (2016) Principles of Bioprocess Control. In: Larroche C, Pandey A, Du G et al. (eds) Current Developments in Biotechnology and Bioengineering: Bioprocesses, Bioreactors and Controls. Elsevier Science, Saint Louis, pp 527-561

35. Pörtner R, Platas Barradas O, Frahm B et al. (2016) Advanced Process and Control Strategies for Bioreactors. In: Larroche C, Pandey A, Du G et al. (eds) Current Developments in Biotechnology and Bioengineering: Bioprocesses, Bioreactors and Controls. Elsevier Science, Saint Louis, pp 463-493

36. Fenila F, Shastri Y (2016) Optimal control of enzymatic hydrolysis of lignocellulosic biomass. Resource-Efficient Technologies 2: S96-S104. https://doi.org/10.1016/j.reffit.2016.11.006

37. Moradi H, Saffar-Avval M, Bakhtiari-Nejad F (2011) Nonlinear multivariable control and performance analysis of an air-handling unit. Energy and Buildings 43: 805-813. https://doi.org/10.1016/j.enbuild.2010.11.022

38. Alford JS (2006) Bioprocess control: Advances and challenges. Computers \& Chemical Engineering 30: 1464-1475. https://doi.org/10.1016/j.compchemeng.2006.05.039 
39. Morales-Rodríguez R, Capron M, Hussom JK et al. (2010) Controlled fed-batch operation for improving cellulose hydrolysis in $2 \mathrm{G}$ bioethanol production. 20th European Symposium on Computer Aided Process Engineering - ESCAPE20

40. Nyttle VG, Chidambaram M (1993) Fuzzy logic control of a fed-batch fermentor. Bioprocess Engineering 9: 115-118. https://doi.org/10.1007/BF00369040

41. Álvarez L, García J, Urrego D (2006) Control of a fedbatch bioprocess using Nonlinear Model Predictive Control. IFAC Proceedings Volumes 39: 347-352. https://doi.org/10.3182/20060402-4-BR-2902.00347

42. Chang L, Liu X, Henson MA (2016) Nonlinear model predictive control of fed-batch fermentations using dynamic flux balance models. Journal of Process Control 42: 137149. https://doi.org/10.1016/j.jprocont.2016.04.012

43. Craven S, Whelan J, Glennon B (2014) Glucose concentration control of a fed-batch mammalian cell bioprocess using a nonlinear model predictive controller. Journal of Process Control 24: 344-357. https://doi.org/10.1016/j.jprocont.2014.02.007

44. Li M (2015) Adaptive Predictive Control by Open-Loop-Feedback-Optimal Controller for Cultivation Processes. Dissertation, Jacobs University

45. Frahm B, Lane P, Märkl H et al. (2003) Improvement of a mammalian cell culture process by adaptive, model-based dialysis fed-batch cultivation and suppression of apoptosis. Bioprocess Biosyst Eng 26: 1-10. https://doi.org/10.1007/s00449-003-0335-z

46. Frahm B, Hass VC, Lane P et al. (2003) Fed-Batch-Kultivierung tierischer Zellen - Eine Herausforderung zur adaptiven, modellbasierten Steuerung. Chemie Ingenieur Technik 75: 457-460. https://doi.org/10.1002/cite.200390093

47. Frahm B, Lane P, Atzert $\mathrm{H}$ et al. (2002) Adaptive, model-based control by the OpenLoop-Feedback-Optimal (OLFO) controller for the effective fed-batch cultivation of hybridoma cells. Biotechnol Prog 18: 1095-1103. https://doi.org/10.1021/bp020035y

48. Zacher S, Reuter M (2017) Regelungstechnik für Ingenieure. Springer Fachmedien Wiesbaden, Wiesbaden

49. Grüne L, Pannek J (2017) Nonlinear Model Predictive Control. Springer International Publishing, Cham

50. Hodge DB, Karim MN, Schell DJ et al. (2009) Model-based fed-batch for high-solids enzymatic cellulose hydrolysis. Appl Biochem Biotechnol 152: 88-107. https://doi.org/10.1007/s12010-008-8217-0 
51. Bück A, Casciatori FP, Thoméo JC et al. (2015) Model-based Control of Enzyme Yield in Solid-state Fermentation. Procedia Engineering 102: 362-371. https://doi.org/10.1016/j.proeng.2015.01.163

52. Luttmann R, Munack A, Thoma M (1985) Mathematical modelling, parameter identification and adaptive control of single cell protein processes in tower loop bioreactors. In: Fiechter A, Aiba S, Bungoy HR et al. (eds) Agricultural Feedstock and Waste Treatment and Engineering, vol 32. Springer, Berlin, Heidelberg, pp 95-205

53. Witte VC, Munack A, MärkI H (1996) Mathematische Modellierung und adaptive Prozeßsteuerung der Kultivierung von Cyathus striatus. Zugl.: Hamburg-Harburg, Techn. Univ., Arbeitsbereich Regelungstechnik und Systemdynamik [i.e. Arbeitsbereich Regelungstechnik] und Arbeitsbereich Bioprozess- und Bioverfahrenstechnik, Diss., 1996, Als Ms. gedr. Fortschritt-Berichte / VDI Reihe 17, Biotechnik, vol 144. VDI-Verl., Düsseldorf

54. Patle DS, Ahmad Z, Rangaiah GP (2014) Operator training simulators in the chemical industry: review, issues, and future directions. Reviews in Chemical Engineering 30. https://doi.org/10.1515/revce-2013-0027

55. Cameron D, Clausen C, Morton W (2002) Dynamic Simulators for Operator Training. In: Braunschweig B, Gani R (eds) Software architectures and tools for computer aided process engineering, 1. ed., vol 11. Elsevier, Amsterdam, pp 393-431

56. Pörtner R, Platas-Barradas O, Gradkowski J et al. (2011) "BioProzessTrainer" as training tool for design of experiments. BMC Proc 5 Suppl 8: P62. https://doi.org/10.1186/17536561-5-S8-P62

57. Gerlach I, Hass VC, Brüning S et al. (2013) Virtual bioreactor cultivation for operator training and simulation: application to ethanol and protein production. Journal of Chemical Technology \& Biotechnology 88: 2159-2168. https://doi.org/10.1002/jctb.4079

58. Reinig G, Winter P, Linge V et al. (1998) Training Simulators: Engineering and Use. Chem Eng Technol 21: 711-716. https://doi.org/10.1002/(SICI)15214125(199809)21:9<711:AID-CEAT711>3.0.CO;2-H

59. Ahmad AL, Low EM, Abd Shukor SR (2010) Safety Improvement and Operational Enhancement via Dynamic Process Simulator: A Review. Chemical Product and Process Modeling 5. https://doi.org/10.2202/1934-2659.1502 
835

836

837

838

839

840

841

842

843

844

845

846

847

848

849

850

851

852

853

854

855

856

857

858

859

860

861

862

863

60. González Hernández Y, Jáuregui Haza UJ, Albasi C et al. (2014) Development of a Submerged Membrane Bioreactor simulator: a useful tool for teaching its functioning. Education for Chemical Engineers 9: e32-e41. https://doi.org/10.1016/j.ece.2014.03.001

61. Gerlach I, Brüning S, Gustavsson R et al. (2014) Operator training in recombinant protein production using a structured simulator model. J Biotechnol 177: 53-59. https://doi.org/10.1016/j.jbiotec.2014.02.022

62. Ahmad Z, Patle DS, Rangaiah GP (2016) Operator training simulator for biodiesel synthesis from waste cooking oil. Process Safety and Environmental Protection 99: 5568. https://doi.org/10.1016/j.psep.2015.10.002

63. Balaton MG, Nagy L, Szeifert F (2013) Operator training simulator process model implementation of a batch processing unit in a packaged simulation software. Computers \& Chemical Engineering 48: 335-344. https://doi.org/10.1016/j.compchemeng.2012.09.005

64. Gerlach I, Mandenius C-F, Hass VC (2015) Operator training simulation for integrating cultivation and homogenisation in protein production. Biotechnol Rep (Amst) 6: 91-99. https://doi.org/10.1016/j.btre.2015.03.002

65. Hass VC, Kuhnen F, Schoop K-M (2005) An environment for the development of operator training systems (OTS) from chemical engineering models 20: 289-293. https://doi.org/10.1016/S1570-7946(05)80170-1

66. Brüning S, Gerlach I, Pörtner R et al. (2017) Modeling Suspension Cultures of Microbial and Mammalian Cells with an Adaptable Six-Compartment Model. Chem Eng Technol 40: 956-966. https://doi.org/10.1002/ceat.201600639

67. R Core Team (2014) R: A language and environment for statistical computing. $R$ Foundation for Statistical Computing, Vienna, Austria

68. Xiong Z-Q, Guo M-J, Guo Y-X et al. (2010) RQ feedback control for simultaneous improvement of GSH yield and GSH content in Saccharomyces cerevisiae T65. Enzyme and Microbial Technology 46: 598-602. https://doi.org/10.1016/j.enzmictec.2010.03.003 